\title{
Nano-Elicitation of Secondary Pharmaceutical Metabolites in Plant Cells: A Review
}

\author{
Hatami M (Ph.D.) ${ }^{1,2^{*}}$, Naghdi Badi H (Ph.D.) ${ }^{3}$, Ghorbanpour M (Ph.D.) ${ }^{1,2}$ \\ 1- Department of Medicinal Plants, Faculty of Agriculture and Natural Resources, \\ Arak University, 38156-8-8349, Arak, Iran \\ 2- Institute of Nanoscience and Nanotechnology, Arak University, Arak, Iran \\ 3- Medicinal Plants Research Centre, Institute of Medicinal Plants, ACECR, Karaj, \\ Iran \\ * Corresponding author: Department of Medicinal Plants, Faculty of Agriculture \\ and Natural Resources, Arak University, Arak, 8349-8-38156, Iran \\ Tel: +98-86-32623420, Fax: +98-86-32771446 \\ Email: m-hatami@araku.ac.ir
}

Received: 3 June 2018

Accepted: 13 August 2018 doi: 10.29252/jmp.3.71.6

\section{Abstract}

In recent years, metabolism researches using nanomaterials have been focusing on human and animal cells, and therefore very limited data are available about influence of nanomaterials on biosynthesis of secondary metabolites in plant cells. Plants produce different types of secondary metabolites including terpenoids, phenolics, tannins, and alkaloids, which are known to act as vital mediators for the interaction with other living (biotic) or non-living (abiotic) agents under stressful conditions. Elicitors may induce physiological and biochemical processes of the target plants and activate defense mechanisms. Application of signaling molecules as elicitors has evolved an efficient technique for the production of pharmaceutically active compounds in plants. However, relatively little has been done regarding the application of nanomaterials as potential elicitors for production of industrially valuable compounds. Here, we provide studies proving that nanomaterials can function as elicitors of plant defensive chemistry that are mostly accompanied by enhanced production of different secondary metabolites.

Keywords: Elicitation, Nanoelicitor, Nanoparticles, Plant secondary metabolites, Reactive oxygen species 


\section{Introduction}

Nanomaterials are specified as materials with external dimensions in the nanoscale or with internal structure or surface structure in the nanoscale. This would qualify most of the materials as nanomaterials, as their internal structure is modulated at the nanoscale. The term nanoscale can be defined as a size range between approximately 1-100 $\mathrm{nm}$ [1].

From the point of view of their dimensionality, nanomaterials are broadly classified in to the three types: with one, two, and three dimensions in the nanoscale regime. Those with one dimension in the nanoscale are very thin films or coatings attached on a substrate. Those with two dimensions in the nanoscale can be porous films with nanoscale pores, long aspect ratio fibers, wires or tubes. Finally, nanomaterials with three dimensions within the nanoscale regime are membranes with nanopores on a substrate, and nanoparticles [2].

Nanoparticles are manufactured for various applications such as medicine, chemistry, biology, electronics, environment, textiles, energy storage, and food and agriculture, and mainly include the following types: (1) Carbon-based nanomaterials such as carbon nanotubes, graphene and fullerenes (C60 and C70); (2) Metal-based nanomaterials including zero-valent metals (e.g. $\mathrm{Au}, \mathrm{Ag}$, and $\mathrm{Fe}$ nanomaterials), metal oxides (e.g. nano-ZnO, $\mathrm{TiO}_{2}$ and $-\mathrm{CeO}_{2}$ ), and metal salts (e.g. nano silicates and ceramics); (3) Quantum dots (e.g. CdSe and CdTe); (4) Nanosized polymers (e.g. dendrimers and polystyrene).

Today's, the range of application of nanomaterials has been expanded in various areas due to their unique properties (Figure 1) such as large surface area-to-volume ratio, ability to engineer electron exchange, extraordinary electronic and optical attributes, and highly surface reactive capabilities [3]. However, our knowledge of the direct interactions between engineered nanomaterials and plant cells is still relatively new [4-7].

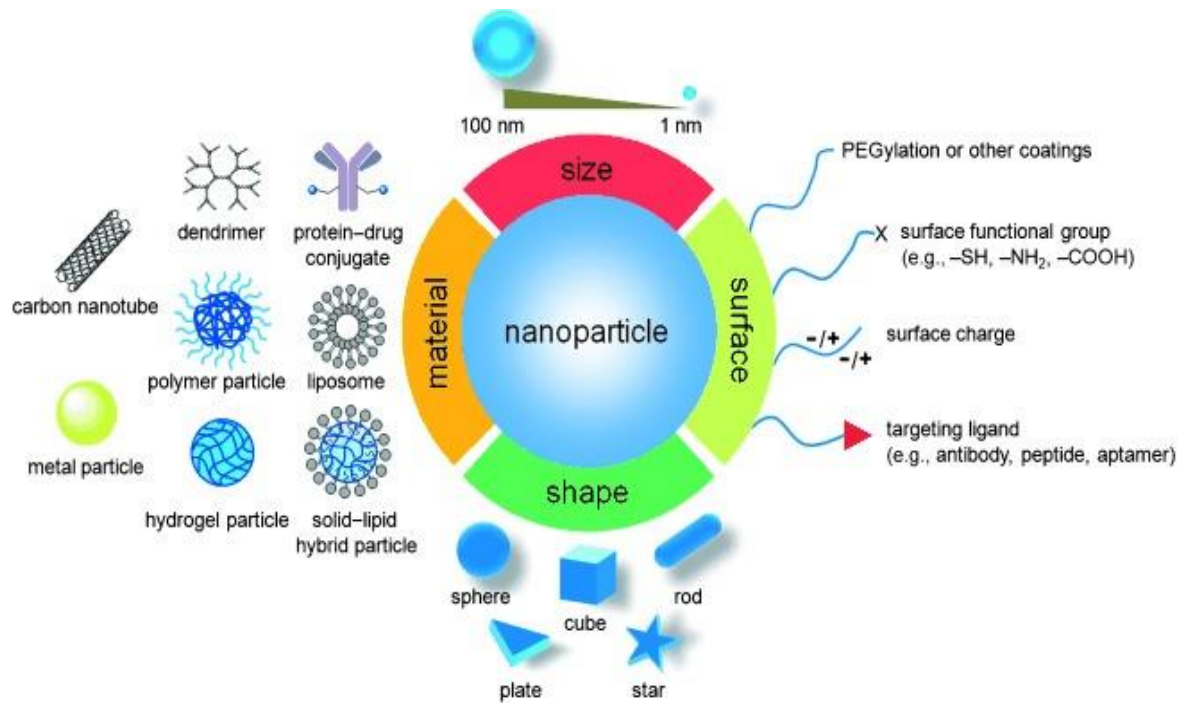

Figure 1- Nanoparticels and their basic characteristics [8] 
A plant cell produces two different kinds of metabolites (Figure 2): primary metabolites involved directly in normal plant growth and metabolic processes including carbohydrates, proteins and lipids, and secondary metabolites/or secondary compounds considered as ultimate products of primary metabolism and not involved in metabolism such as alkaloids, phenolics, essential oils, sterols, steroids, lignins and tannins, etc. Plant secondary metabolites are organic substances that are not directly involved in growth and development as well as in reproduction; rather, they play some crucial role in different signaling cascades, defense mechanism against microorganisms, etc. Secondary plant products are considered for their important function in the survival of the plant in its ecosystem, time and again protecting plants against pathogen attack, insect attack, mechanical injury, and other types of biotic and abiotic stresses [9]. It has been acknowledged that most of these plant secondary metabolites have some beneficial role in the human body, therefore, these are considered as phytomedicines.

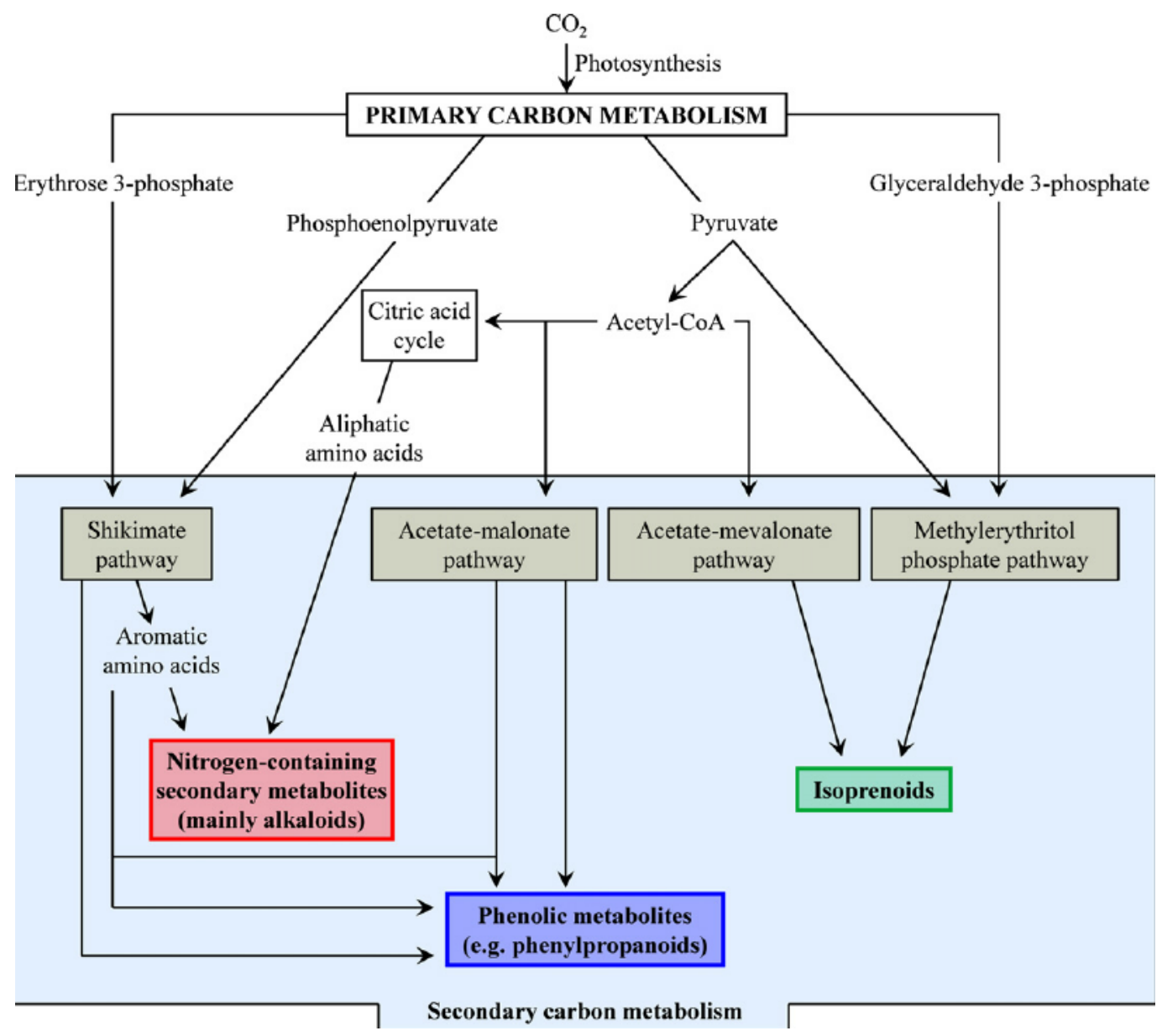

Figure 2- A simplified model of the pathways involved in the biosynthesis of secondary metabolites [10] 
Usually, secondary metabolites, a rich source of pharmaceuticals with defensive properties, are synthesized by plants when exposed to different elicitors and/or inducer molecules [11, 12]. Nowadays, various biotic and abiotic elicitors are practiced to trigger and concentrate the secondary metabolites and cell volume in suspension culture [13]. Among the various strategies available to increase the levels of metabolite of interest, application of elicitors in suspension culture is mostly trusted and practiced strategy. Elicitors in a precise concentration can be administered at desirable time to the suspension culture, resulting in achieving the highest levels of metabolite in a short span of time [14].

Nanomaterials have the great potential to be applied as novel effective abiotic elicitors in plant biotechnology for inducing the biosynthesis of secondary metabolite [15]. In recent years, many researchers have studied the nano-elicitive role of nanomaterials as elicitors for secondary metabolite production in plant cell and tissue cultures [16-25]. Furthermore, a number of studies have affirmed the possible function of nanomaterials as elicitors for increasing the expression level of involved genes in biosynthesis of secondary metabolites [23, 25]. Nanoscale materials have successfully offered a new approach in improving plant secondary metabolite production [26]. However, still indepth and consolidate guidance and practical advice in research are required to elucidate the impacts of nanomaterials in elicitation mechanisms of secondary metabolites in medicinal and aromatic plants.

\section{Uptake and translocation of nanoparticles to plant cell}

To fully understand the nature of nanoparticle-plant interactions, it is necessary to deeply characterize the entry, uptake, translocation, accumulation, biotransformation and fate and risks of these materials inside plant cells, tissues and organelles. Many factors affect the plant uptake of nanoparticles such as exceptional characteristics of nanoparticles, interaction of the nanoparticles with the environment, and plant physiological indices (Figure 3).

Nanoparticles may form complexes with transporter plasma membrane proteins or root exudates which mediate nanoparticles localization into the xylem vessels [27].

Physicochemical properties of nanomaterials such as surface roughness and charge, and hydrophobicity degree promote surface binding and the subsequent cellular uptake of nanoparticles. The entry and transportation of nanoparticles may happen via root to leaf/fruit (below- to aerial organs) or leaf to root (aerial to below-ground organs) pathways [28], a key point that makes both foliar and soil applications feasible in plantsoil ecosystems.

When exposed to plant roots (soil mixednanoparticles entry rout), nanoparticles transport may occur through both apoplastic and symplastic pathways [29]. In order to allow the direct penetration of nanoparticles, the cell wall pore size should be less than 20 $\mathrm{nm}$ in diameter, [30], therefore; larger particles would have limited ability to enter epidermal cells. After penetrating the cell walls, 
Hatami \& et al.

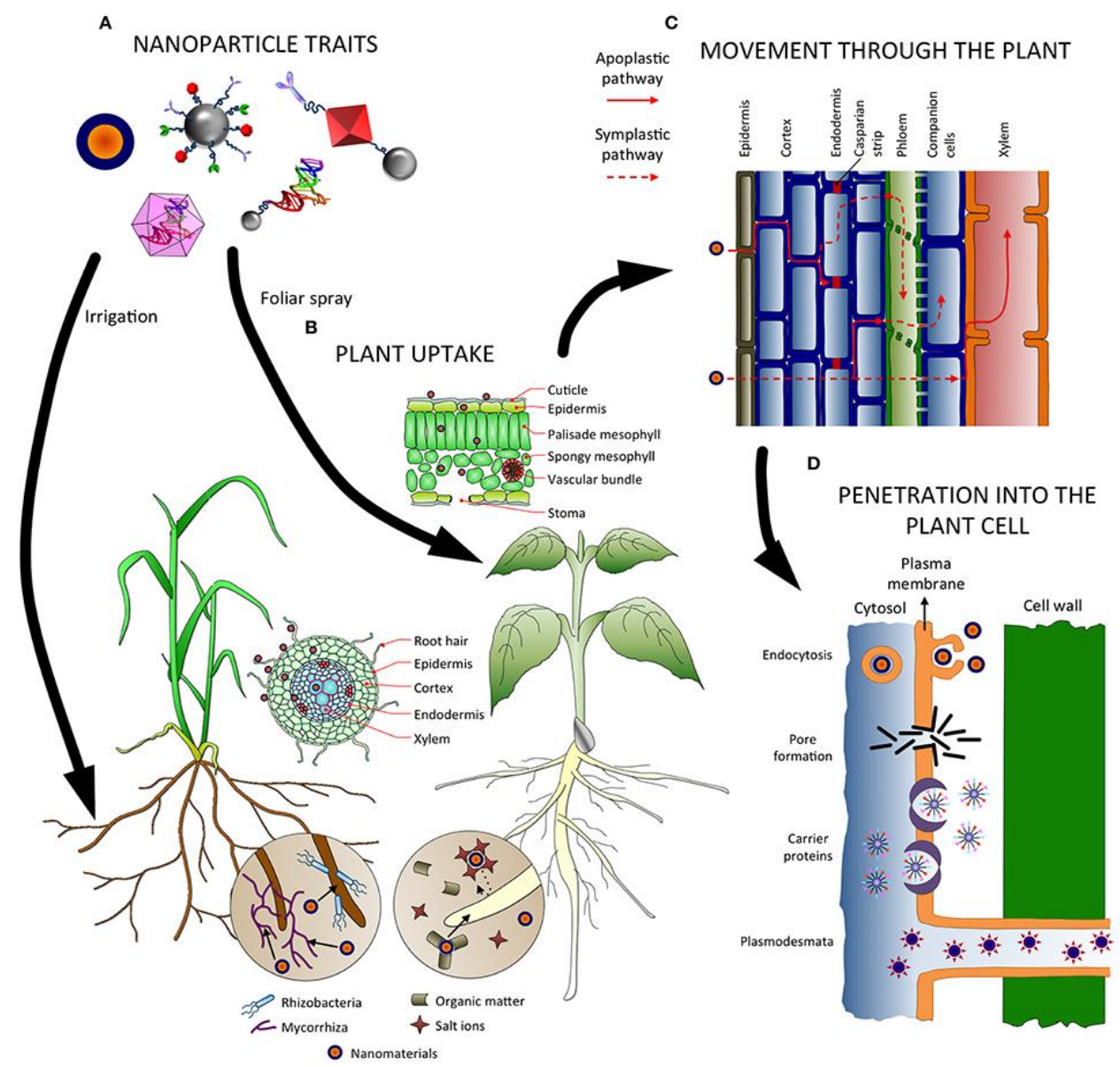

Figure 3- Multiple factors affecting nanoparticles uptake, translocation and penetration in plants. (A) Characteristics of nanoparticles influence on their uptake and transportation in the plant tissues, and different procedures of nanoparticles application. (B) Interaction of nanoparticles with soil microorganisms and compounds. (C) Various pathways of nanoparticles translocation in plants (D) Nanoparticles internalization ways in plant cells [42].

nanoparticles may be diffused between cell walls and plasma membrane, and their subsequent movements may be regulated by two forces, osmotic pressure and capillary exchange [31]. Other than transporter proteins (carriers) such as aquaporins (water channels) and the presence of ion channels, nanoparticles can also reach inside the cells through endocytosis or membrane piercing processes [32].

Endocytic uptake (a type of active transport) process occurs where specific receptor-ligand binding interactions happen. On the basis of their morphology, engineered nanomaterials such as carbon nanotubes are able to enter the cytoplasm of cells by directly piercing the membrane [33]. Within the cytoplasm, nanoparticles interact dynamically with the surrounding environment through several forces such as van der Waals, electrostatic, hydrogen bonds, solvation forces, and steric-polymer interactions. Subsequently, protein molecules bind onto nanoparticles surfaces and constitute complex structures referred to as protein corona [34]. The protein corona may affect cellular uptake, accumulation/ aggregation, and degradation of the nanoparticles [35]. These internalized 
nanoparticles-endosome or nanoparticlesprotein complexes may transfer to neighboring plant cells via small channels called plasmodesmata [29]. The cytoskeleton microfilaments reorganization may be interrupted by nano-scale titanium dioxide $\left(\mathrm{TiO}_{2}\right)$ exposure, influencing the plasmodesmata sustainability [36].

Once inside the cells, nanoparticles may interact with organelles and disrupt the metabolic processes, produce oxidative stress, and genetic modifications.

When applied to the foliage of the plant (aerosol-nanoparticles entry rout), nanoparticles were capable of penetrating leaves through stomatal pores [37-39]. For instance, evidences of the internalization were observed in lettuce leaves exposed to Ag [37] and $\mathrm{TiO}_{2}$ [38] nanoparticles. From the initial sites of exposure/entry, nanoparticles could be subsequently translocated to other parts and vascular tissues such as roots [39]. The cellular internalization of nanoparticles in suspension culture systems, may occur through a mechanism primarily based on fluid phase pinocytosis, which is the inclusion of solutes from the apoplast to the vacuole occurred through vesicles formation at the plasma membrane [40, 41].

After penetration into plant cells, nanoparticles interact with intracellular components/molecules, organelles and structures. The nature of interaction between nanoparticles and two target cell organelles namely chloroplasts and mitochondria, could be chemical or physical variations. Both type of nanomaterials (i.e., carbon-based and metalbased) are able to induce stress and produce excessive reactive oxygen species (ROS), which subsequently affect cell organelles and structures, DNA, proteins, carbohydrates, lipids, and secondary metabolites in plants [43, 44]. As presented in Figure 4, nanomaterials can cause toxic effects on plants at both the

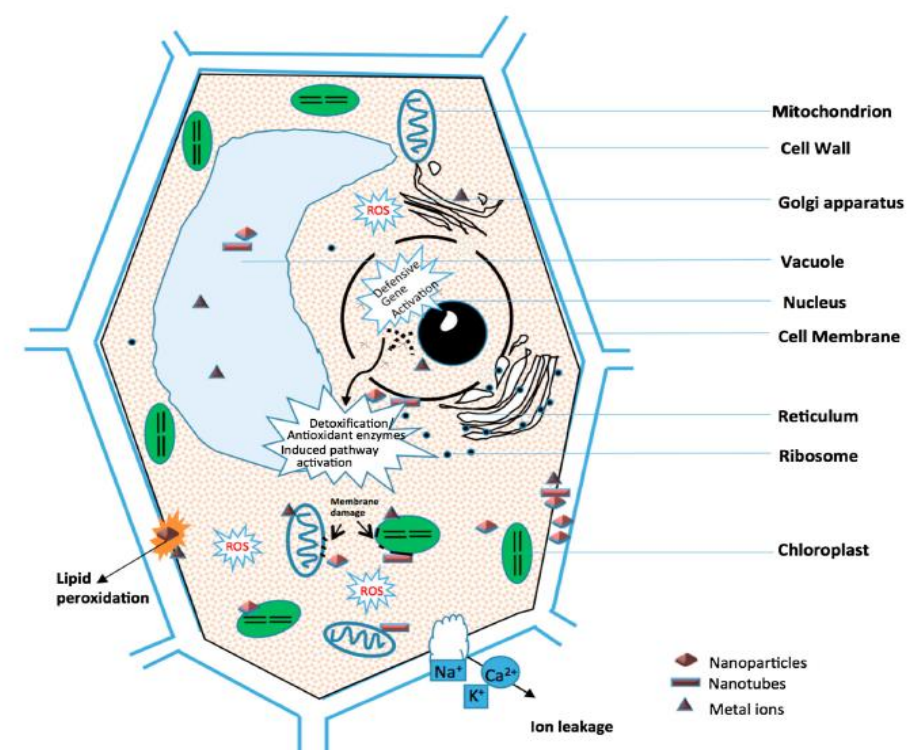

Figure 4- Schematic model of potential cellular damages and subsequent detoxification mechanisms under nanoparticles exposure [48]. 
cellular (cell membrane and chromosomal damage, and chlorophyll biosynthesis disruption) and physiological (biomass reduction, root length inhibition, etc.) levels [45-47]. Many researchers have extensively devoted their efforts to recognize the exact mechanisms of plant defense systems against nanomaterials-induced oxidative stress. Although, rapid progress has been made worldwide in recent years, there are many uncertainties and gaps in our present knowledge of ROS-dependent injury and its impacts on plant cells. It is critical to understanding and evaluating nanoparticles toxicity, and triggering the antioxidant defense systems as major plant response mechanisms.

\section{Interaction of nanoparticles with plant cells}

In order to enter the symplastic (inner side of the plasma membrane) pathway, nanoparticles should be internalized through the plant cell and cross the plasma membrane (Figure 5). There are several routs for nanoparticles to attain this [32, 49]:

- Endocytosis: The nanoparticles are included into the cell by invagination (inner folding) of the plasma membrane, developing a vesicle that can move to various compartments of the cell [50].

- Pore formation: Nanoparticles are able to interrupt the plasma membrane, forming pores for passing into the cell [51] and arriving

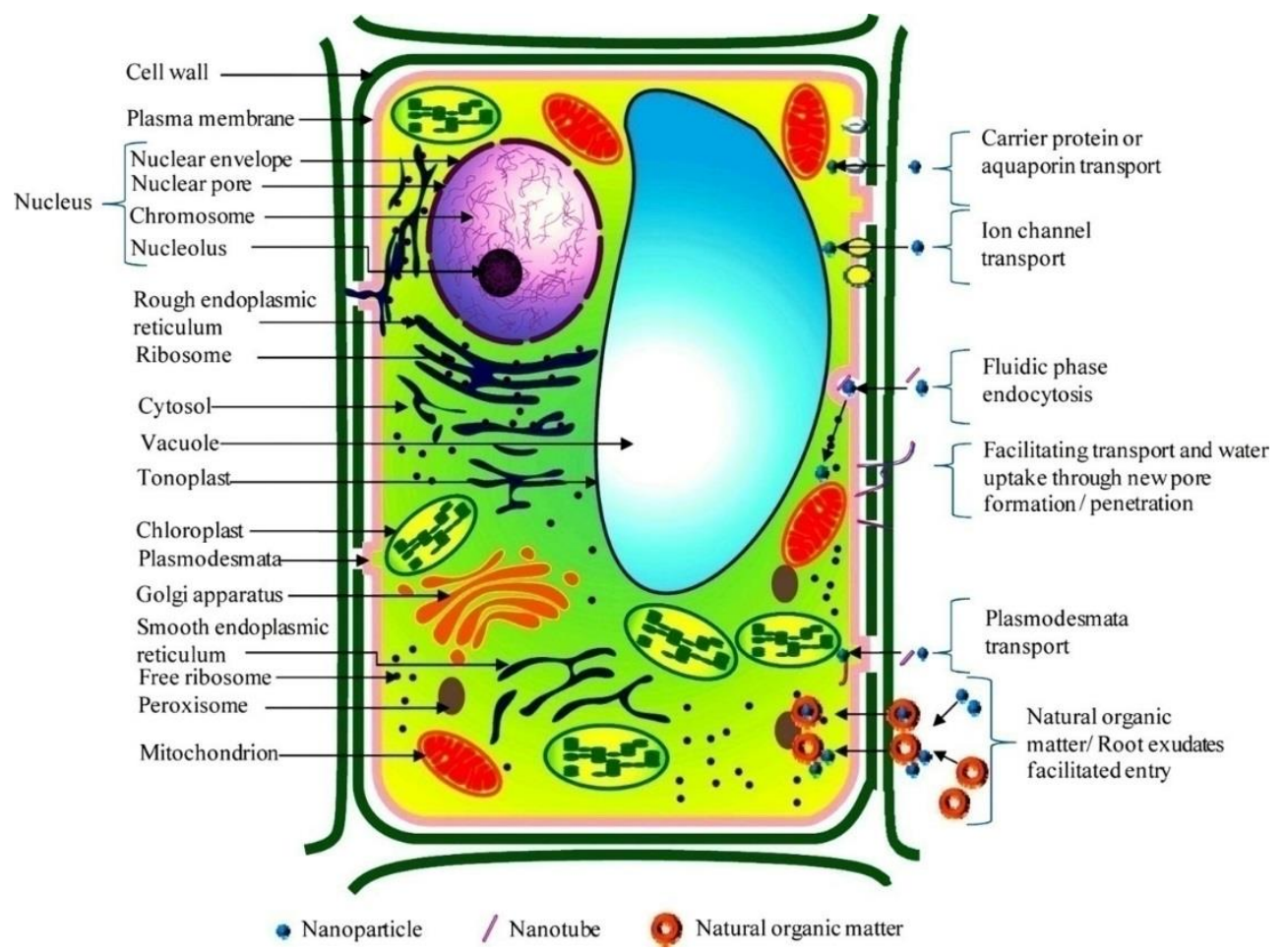

Figure 5- The possible pathways of nanoparticles uptake in a plant cell [32]. 
directly into the cytosol without being encapsulated in any cell organelle [52].

- Carrier proteins: Nanoparticles can wrap to surrounding proteins, comprising cell membrane proteins that could perform as carriers for internalization and uptake within the cell [34]. Particularly, aquaporins (water channels) have been suggested as transporters of nanoparticles within the cell [32], but their small pore size (2.8-3.4 $\AA$ ) [53], makes them implausibly as channels for nanoparticle penetration [49], unless such pore size could be modified and enlarged.

- Plasmodesmata: Nanoparticles can reach to the cell through another path called plasmodesmata (narrow channels that act as intercellular cytoplasmic bridges to facilitate communication and transport of materials between plant cells) $[54,55]$.

- Ion channels: These are pore-forming membrane proteins that allow ions to pass through the channel pore, and it has been proposed as probable pathways for nanoparticles entry into the cell [32, 49]. However, the size of such channels is around 1 $\mathrm{nm}$, which makes very improbably for nanoparticles to effectively cross them without important modifications; therefore, particles with larger size would have limited ability to enter cells [56].

\section{Biosynthesis of plant secondary metabolites upon exposure to nanomaterials}

\section{Alkaloids}

Alkaloids are among a group of naturally occurring chemical compounds of plant cells that are affected via exposure to different types of nanoelicitors. Ghorbanpour et al. (2015) reported that titanium dioxide nanoparticles $\left(\mathrm{TiO}_{2}\right.$ NPs, 10-15 nm) and their bulk counterparts $\left(\mathrm{TiO}_{2}\right.$ BPs $)$ act as elicitors for elicitation of two main tropane alkaloids including hyoscyamine and scopolamine in black henbane (Hyoscyamus niger L.) at concentrations of 20,40 and $80 \mathrm{mg} / \mathrm{L}$. They reported that at the highest $\mathrm{TiO}_{2}$ concentration (80 $\mathrm{mg} / \mathrm{L})$, the maximum content of hyoscyamine $(0.286 \mathrm{~g} / \mathrm{kg})$ was observed compared to plants exposed to $\mathrm{TiO}_{2}$ BPs $(0.161 \mathrm{~g} / \mathrm{kg})$, whereas, maximum scopolamine content reached to peak at the lowest $\mathrm{TiO}_{2} \mathrm{NPs}$ concentration. Moreover, application of $\mathrm{TiO}_{2}$ NPs at $40 \mathrm{mg} / \mathrm{L}$ increased the total alkaloids yield 2.5 times than control, mainly due to higher accumulation of biomass and improved biosynthesis of alkaloids under such conditions [57]. Activation of rate limiting enzymes involved in biosynthetic pathway of tropane alkaloids such as putrescine $\mathrm{N}$ methyltransferase and hyoscyamine $6 \beta$ hydroxylase, are expected to be affected as a result of exposure to nanoscale materials, suggesting the metabolic adaptation of exposed plants in response to the negative impacts induced by these nanoscale particles. However, there is no or little evidence available about reversibility and adaptation approaches to nanotoxicity in exposed plants, which are still controversial issues and warrant further researches. Elicitation of secondary metabolites in some of the plant species upon exposure to nanoparticles is given in Table 1.

The toxicity of silver nanoparticles (AgNPs) has been attributed to different 


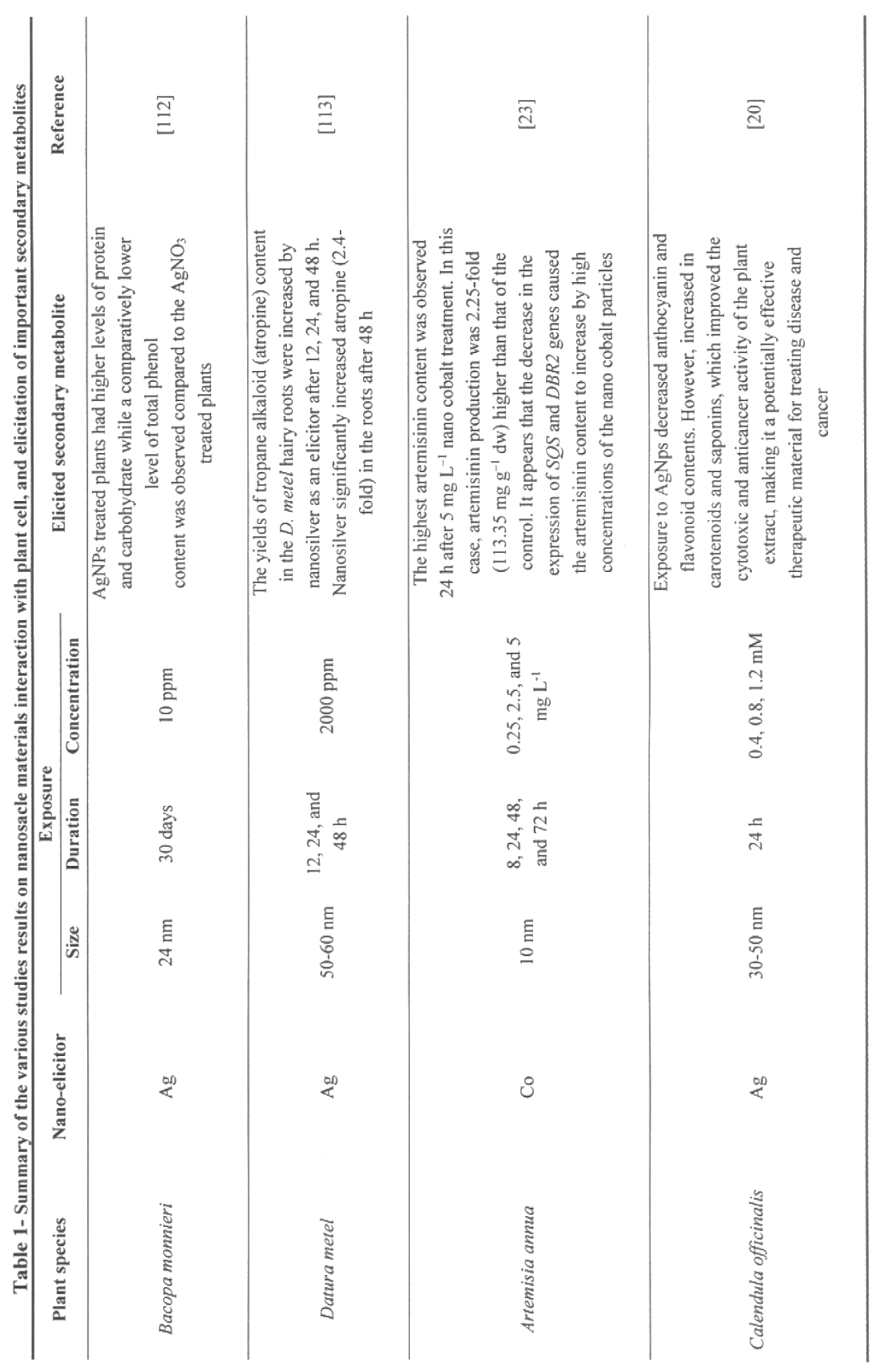

Journal of Medicinal Plants, Volume 18,
No. 71, Summer 2019 


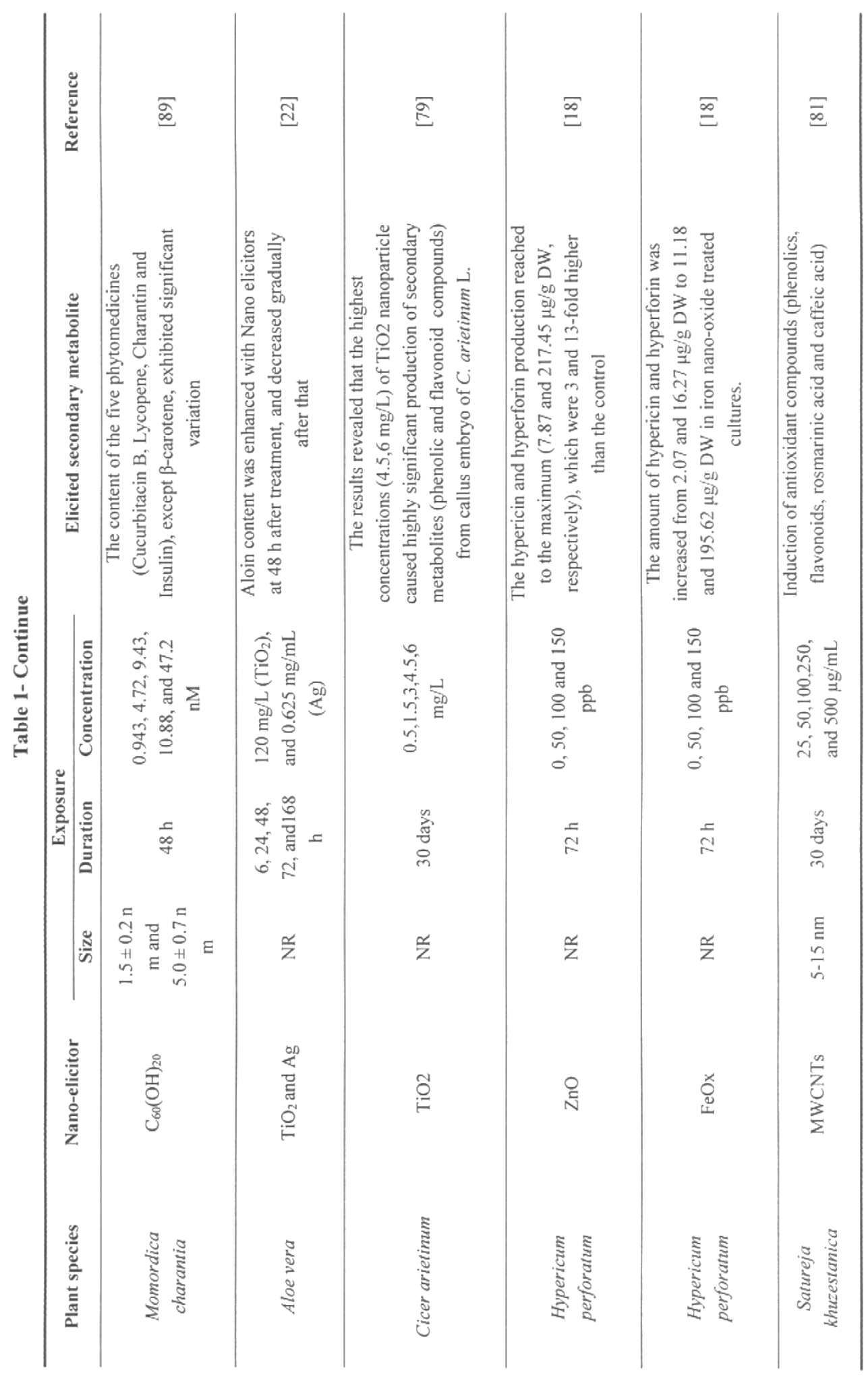


Hatami \& et al.

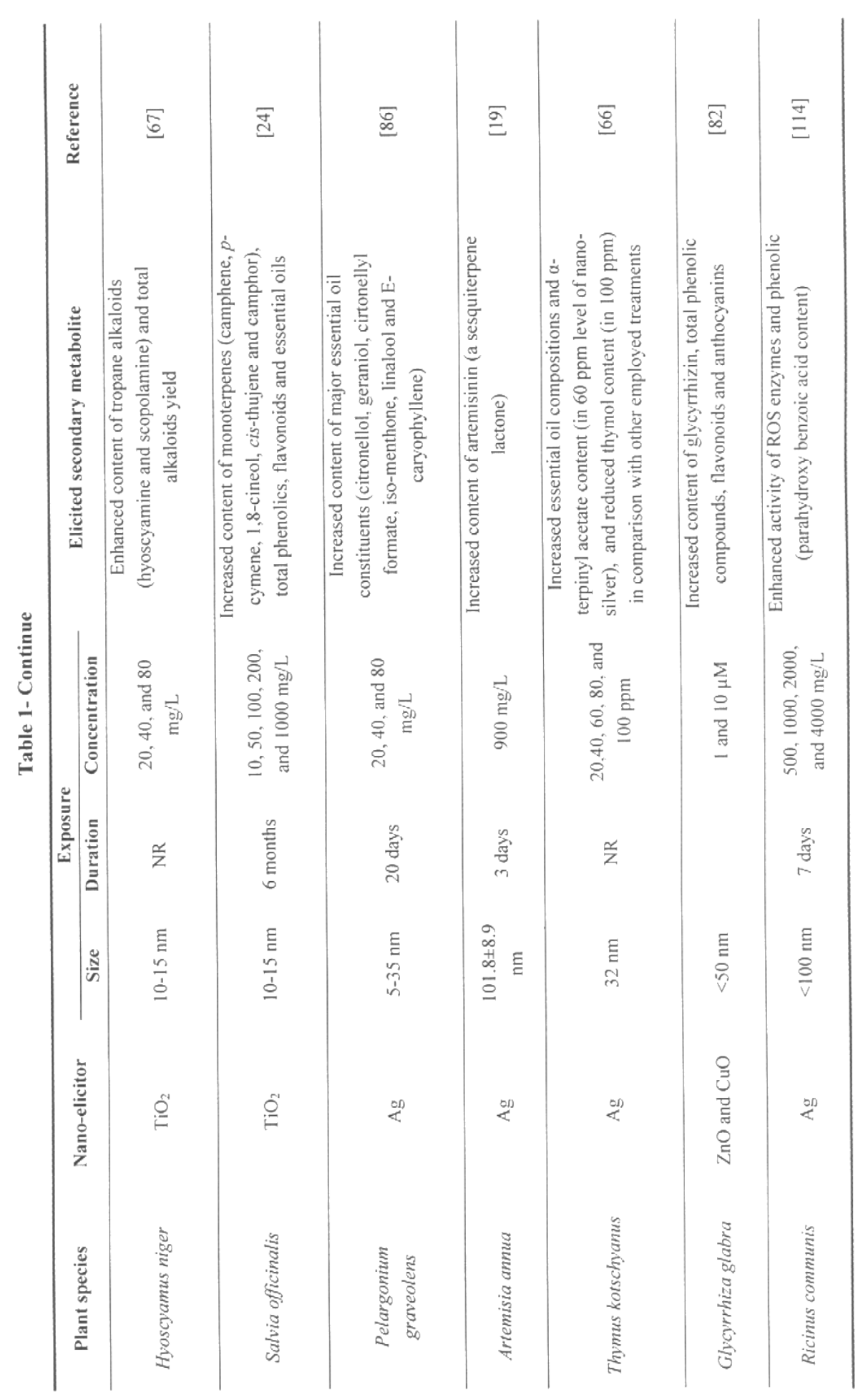

Journal of Medicinal Plants, Volume 18,
No. 71, Summer 2019 


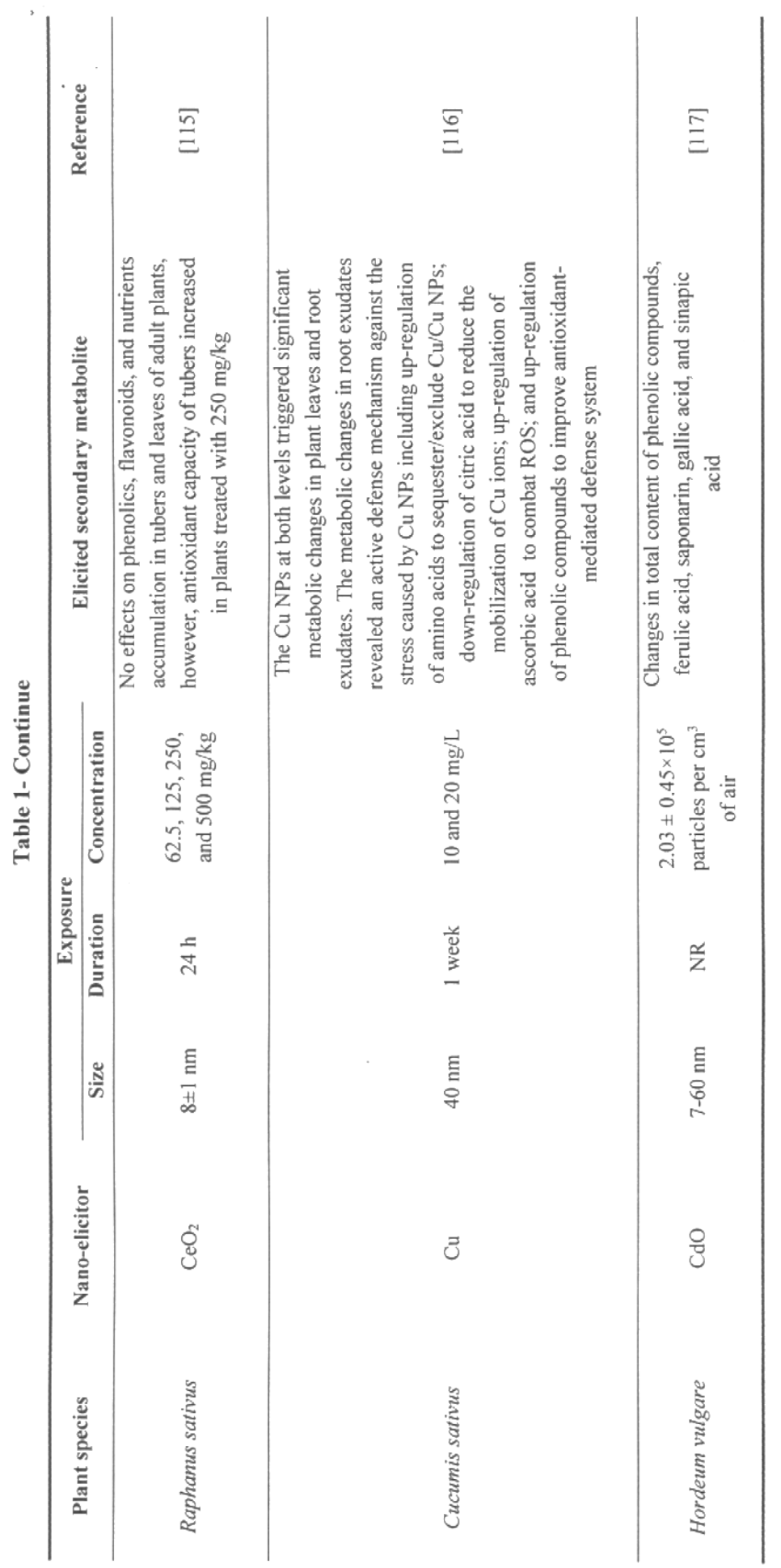


Hatami \& et al.

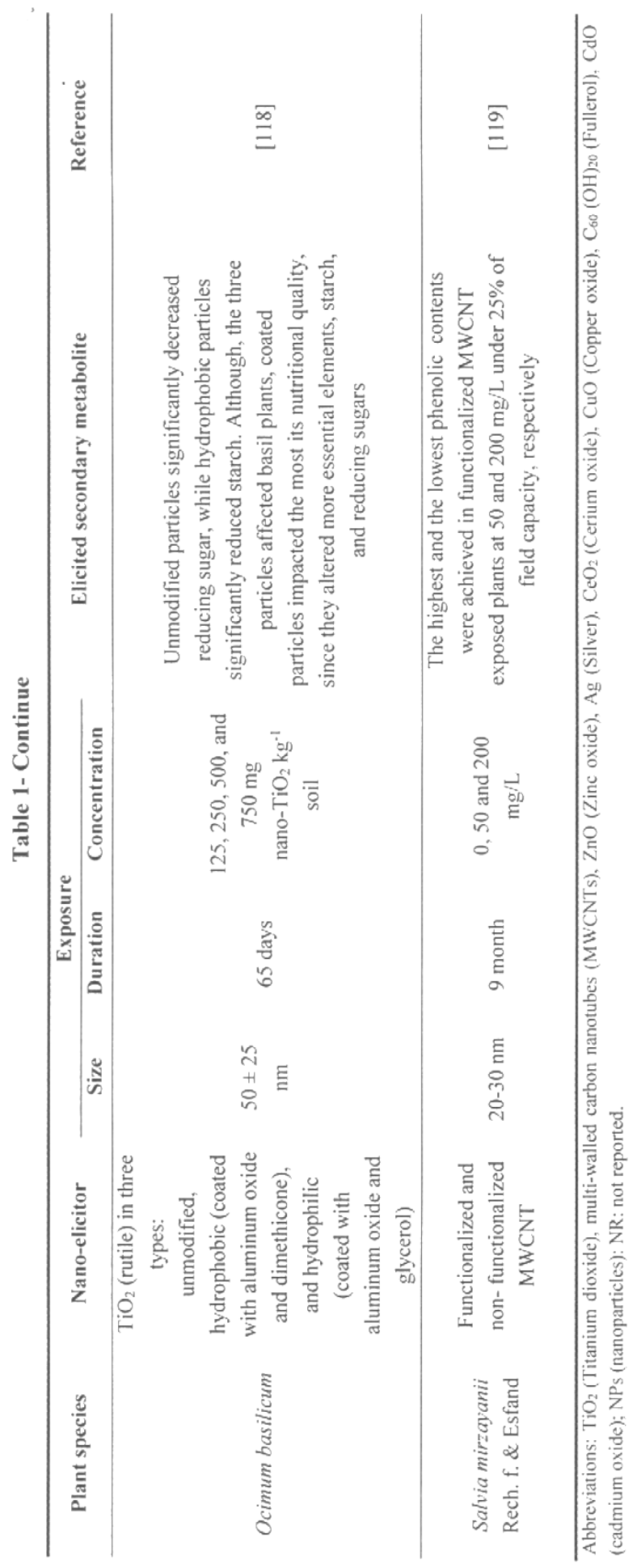

Journal of Medicinal Plants, Volume 18,
No. 71, Summer 2019 
mechanisms including production of $\mathrm{Ag}^{+}$ions and generation of ROS, eliciting defense responses of plant cells in different ways such as improvement of secondary metabolite biosynthesis [19]. This hypothesis was evaluated by Jamshidi and Ghanati [58] through assessment of taxanes production using suspension-cultured hazel (Corylus avellana L.) cells exposed to AgNPs. The cultures were exposed to $\operatorname{AgNPs}(0,2.5,5$, and10 ppm), during the logarithmic growth phase (d7) of cells and were harvested after 1 weak. The membrane stability and growth of cells decreased, but extracellular electro conductivity and total dissolved solids increased following exposure to AgNPs mainly due to membrane disruption. Treatment of hazel cells with AgNPs (in particular of 5 ppm) rapidly and remarkably increased the yields of two major taxanes, i.e., taxol and baccatin III; so that $24 \mathrm{~h}$ of the treatment their contents reached to $378 \%$ and $163 \%$ of the control, respectively. Increase of taxanes was accompanied by the increase of total soluble phenols [58].

\section{Phenylpropanoids and terpenoids}

In a study by Amuamuha et al. (2012), the effect of varying concentrations and time of nanoiron foliar application was investigated on the essential oil of pot marigold. Four concentrations $\left(0,1,2\right.$, and $\left.3 \mathrm{~g} \mathrm{~L}^{-1}\right)$ of iron NPs were used for spraying at different stages (foliar application at stem initialize, flowering, and after the first and second harvest) [59]. Significant influence of spraying time (growth stage) on the essential oil percent was observed at the first harvest and the essential oil yield at the third harvest. Similarly, nanoiron concentrations showed significant effect on the yield of essential oil at the first harvest. The highest percentage $(1.573 \%)$ of essential oil was reported when nanoiron was applied at the early stage (stem initialized) led to the maximum yield of essential oil (2.397 $\left.\mathrm{kg} \mathrm{ha}^{-1}\right)$ in the flower. The lowest essential oil percentage $(0.981 \%)$ was recorded when nanoiron was applied at later stages (after the second harvest).

It has been acknowledged that nanosilver particles act as a novel and effective elicitor in plant biotechnology for the production of plant secondary metabolites [19]. Exposure of Ag$\mathrm{SiO}_{2}$ core-shell nanoparticles (AgNPs) enhanced artemisinin content in the hairy root culture of Artemisia annua. Recent investigations have reported the potential of lipid nanoparticles for parenteral delivery and the augmentation of antimalarial potential of artemether, a derivative of artemisinin [16, 60]. Influence of nanocobalt on the expression level of involved genes and content in Artemisia was examined [23]. Nanocobalt particles were used for the elicitation of artemisinin in the cell suspension culture of A. annua qRT-PCR and HPLC were used for quantification of the expression levels of SQS and DBR2 genes and artemisinin content in cell suspension culture, respectively. For this purpose, different concentrations $(0.25,2.5$, and $5 \mathrm{mg} \mathrm{L}^{-1}$ ) of nanocobalt particles were used and samples were analyzed after 8, 24, 48, and $72 \mathrm{~h}$. The maximum increase (2.25fold, i.e., $113.35 \mathrm{mg} \mathrm{g}^{-1} \mathrm{dw}$ as compared to control) in artemisinin content was recorded when cells were exposed to $5 \mathrm{mg} \mathrm{L}^{-1}$ 
nanocobalt for $24 \mathrm{~h}$. At the same time, suppressed expression of SQS and DBR2 genes was observed. This decline in the expression of SQS and DBR2 genes might be the cause of enhanced production of artemisinin content by high concentrations of the nanocobalt particles. The mechanism of the impact of nanocobalt on enhancing artemisinin content will be unstated with the expression analysis of all genes involved in artemisinin production [23]. However, to increase the production of a metabolite, enhancing the expression of particular one gene is not sufficient.

Yarizade and Hosseini (2015) examined the effect of nanocobalt and nanozinc $(0,0.25,0.5$, and $1 \mathrm{mg} \mathrm{L}^{-1}$ ) on the expression levels of ADS, DBR2, ALDH1, and SQS genes at 8, 24, 48, and $72 \mathrm{~h}$ after treatment in the hairy root culture of A. vulgaris. It has been reported that application of $0.25 \mathrm{mg} \mathrm{L}^{-1}$ cobalt nanoparticles caused the maximum expression for all genes under investigation, whereas nanozinc $(1.0 \mathrm{mg}$ $\mathrm{L}^{-1}$ ) particles caused the maximum gene expression. Potential application of nanozinc and nanocobalt oxide as elicitor to increase artemisinin production in biological systems such as hairy roots was suggested. Nanocobalt was recommended as the better elicitor compared to nanozinc, since concurrent to the increase in the ADS upregulation; subsequently, it down regulates its antagonist, the SQS gene [25]. Baldi and Dixit (2008) stated a slight increase in the artemisinin content of artemisia cell suspension upon the addition of yeast extract [61]. This increase was credited to the presence of metal ions $\mathrm{Co}^{2+}$ and $\mathrm{Zn}^{2+}$. More researches are required to understand the exact mechanisms of cell elicitation of secondary metabolites in response to nanoparticles treatment $[11,12]$.

Bahreini et al. (2015) analyzed the phytoconstituents of in vitro grown fennel plantlets in normal and nanoelicited $\left(\mathrm{TiO}_{2}\right.$ and $\mathrm{SiO}_{2}$ ) conditions [62]. A significant difference was observed among the metabolites of normal and elicited conditions. The major components of normal plant were anethole, fenchone and limonene and decane. Some identified constituents of $\mathrm{TiO}_{2}$-elicited plant extract were dodecane, phytol, and phenol 2,4 bis $(1,1$ dimethyl ethyl), and the most frequent compound was octane. In plants elicited with $\mathrm{SiO}_{2}$, benzoic acid, jasmonic acid, and hexadecanoic acid were detected as elicited plant components and the major compound was pyrrolidinone. Some of other accumulated metabolites, which appeared by elicitor inductions such as phytol and benzoic acid, can be used as pharmaceutical and industrial precursors [62]. Aromatic constituents are derived from phenylpropane hydrocarbons. The major identified components of fennel oil are phenyl propanoids and terpenoids. One of the major compounds of fennel volatile oil is trans-anethole, the amount of which is the major governing factor for the quality of fennel volatile oil [63, 64, 65]. Similarly, Zhang et al. (2013) showed that AgNPs considerably enhanced the production of artemisinin (a sesquiterpene lactone) in $A$. annua hairy root culture. Up to now, very little study has been performed to determine the impacts of nanoparticles on essential oil production of exposed plants [19]. However, Ghorbanpour (2015) reported enhanced 
essential oil content (\%) and yield (g/plant) of Salvia officinalis upon exposure to employed concentrations of $\mathrm{TiO}_{2} \mathrm{NPs}$. Specifically, at moderate concentration $(200 \mathrm{mg} / \mathrm{L}), \mathrm{TiO}_{2} \mathrm{NPs}$ caused the highest essential oil content and yield, 1.75 and 2.74-folds higher than those of untreated controls, respectively. Also, two major composition of the essential oils, cisthujene and 1,8-cineol, were peaked in plants exposed to $200 \mathrm{mg} / \mathrm{L} \mathrm{TiO}_{2} \mathrm{NPs}$. The same author suggested that enhanced plant biomass and biosynthesis of certain types of terpenes following exposure to $\mathrm{TiO}_{2} \mathrm{NPs}$ directly increased essential oil yield per plant [24].

Aghajani et al. (2013) reported the impacts of AgNPs ( $32 \mathrm{~nm}$ ) exposure (3 hours at 20, $40,60,80$ and $100 \mathrm{ppm}$ ) on production of essential oils in Thymus kotschyanus in a pot experiment. Upon exposure, minor components of essential oils were not significantly changed with experimental treatments. However, major compounds of essential oils such as $\alpha$-terpinyl acetate were increased at the $60 \mathrm{ppm}$ exposure. Furthermore, thymol content was more than twice of carvacrol at all employed concentrations of AgNPs except at 100 ppm [66]. Similarly, Zhang et al. (2013) reported an increase in artemisinin content of Artemisiaannua hairy root culture after 3 days of exposure to $900 \mathrm{mg} / \mathrm{L}$ AgNPs [19].

According to the existing literature, few studies have been performed on the coexposure of nanoparticles and other chemicals on plant metabolism, and the synergistic or antagonistic interactions between them are not well known. In a study, Ghorbanpour and Hatami investigated the effects of different concentrations (20, 40 and $80 \mathrm{mg} / \mathrm{L})$ of AgNPs $(5-35 \mathrm{~nm})$ and thidiazuron (TDZ: 0, 50, 75 and $100 \mu \mathrm{M})$ and their combinations on bioaccumulation of essential oil constituents in geranium (Pelargonium graveolens) plants [67]. Application of AgNPs and TDZ caused significant changes in the essential oil quantity and quality. The highest content of essential oils and maximum values of major essential oil constituents, citronellol (C) and geraniol (G), were observed upon co-exposure to $\mathrm{AgNPs}_{80}+\mathrm{TDZ}_{100}$. However, $\mathrm{AgNPs}_{40}+$ $\mathrm{TDZ}_{75}$ co-exposure exhibited $\mathrm{C} / \mathrm{G}$ ratio equal to one, indicating the positive synergistic interactions upon AgNPs and TDZ coexposure on quality of essential oils. It is necessary to mention that essential oil with $\mathrm{C} / \mathrm{G}$ ratio equivalent to one possesses a good odor and fragrance, therefore, favored by different industries such as perfumery, pharmaceutical, food, and cosmetic [68, 69]. The authors suggested a dose-dependent increased generation of $\mathrm{H}_{2} \mathrm{O}_{2}$ with application of AgNPs and/or TDZ, which subsequently play a vital role in accumulation of secondary metabolites. Essential oil yield was significantly positively correlated with photosynthetic pigments such as chlorophyll and carotenoids. Subsequently, higher chlorophyll concentrations coupled with an increase in photosynthesis rate, leading to boost primary metabolites (e.g. carbohydrates) levels. Carbohydrates metabolism include complex biochemical pathways responsible for triggering secondary metabolism in P. graveolens plant [70]. The authors concluded that co-exposure of nanomaterials (e.g. Ag NPs) with plant growth regulators 
(e.g. TDZ) at appropriate concentrations could be a promising technique in the field of plant metabolic engineering.

\section{Flavonoids and phenolics}

Phenolics and flavonoids constituents are biologically, pharmaceutically and economically valuable compounds that are synthesized through the shikimatephenylpropanoids-flavonoids pathway in terrestrial higher plants. These metabolites exhibit free radical (ROS) scavenging activities and protective role against oxidative damage caused by elicitors mostly due to their redox characteristics [71].

Raei et al. (2014) studied the effects of different abiotic elicitors including nano- $\mathrm{Ag}$, nano- $\mathrm{TiO}_{2}, \mathrm{NH}_{4} \mathrm{NO}_{3}$, and sucrose on cell suspension culture of Aloe vera. This plant contains various secondary metabolites, and the most important of them is aloin (an anthraquinone), which displays antimicrobial activity against some bacteria and fungi, and possesses healing ability of skin burns, ulcer, and cutaneous injuries [72, 73]. The induced calli of $A$. vera by aforesaid elicitors was collected at five intervals $(6,24,48,72$, and $168 \mathrm{~h}$ ). Enhanced production of aloin was observed in $48 \mathrm{~h}$ after elicitation with AgNPs, but this level was gradually reduced with time and reached the control level. This reduction might be related to the feedback of aloin on the gene expression, and increased production of aloin is the reason for down-regulation of gene expression [22]. Titanium dioxide $\left(\mathrm{TiO}_{2}\right)$ nanoparticles could increase the aloin content in $48 \mathrm{~h}$ after elicitation but declined to a lower level, $8.8 \%$, than the control. The reduction may be due to the toxic effect of nano- $\mathrm{TiO}_{2}$ in the culture medium or on gene expression. However, both (nano-Ag and $\mathrm{TiO}_{2}$ ) of the nanoelicitors enhanced the aloin content $48 \mathrm{~h}$ after treatment but after that reduced gradually. Krishnaraj et al. (2012) studied the effect of biologically synthesized (biogenic) AgNPs on metabolism of Bacopa monnieri (Linn.) (Brahmi). Total phenol content was assayed in different parts of the plants grown in hydroponic solution, and improved total phenol content was reported in plants exposed to AgNPs. Results showed that treatment with biogenic Ag NPs exerted a slight stress condition on the growth and metabolism of $B$. monnieri, and therefore, increased phenol content is one of the mechanisms to mimic mild stress condition [74]. Enhancement of polyketides from Hypericum perforatum is widely used to treat mild-to-moderate depression [75, 76]. Hypericin and hyperforin are naphthodianthrones and prenylated acylphloroglucinols, respectively, placed under polyketides. Several elicitors for the production of hypericin and hyperforin in cell cultures of $H$. perforatum have been studied. Iron- and zinc-nano oxides were used as elicitors for the first time by Sharafi et al. (2013). Different concentrations of zinc- and iron-nano oxides $(0,50,100$, and $150 \mathrm{ppb})$ were used for the treatment, and samples were analyzed after $72 \mathrm{~h}$. It has been reported that zinc- and iron-nano oxides (at $100 \mathrm{ppb}$ ) augmented the hypericin and hyperforin production in cell suspension culture of $H$. perforatum [18]. In the cultures supplemented with zinc oxide nanoparticles, the hypericin and hyperforin content reached 
to the maximum (7.87 and $217.45 \mu \mathrm{g} \mathrm{g}^{-1}$ dry weight, respectively), which were 3- and 13folds higher than those of control. The amount of hypericin and hyperforin was increased from 2.07 and $16.27 \mu \mathrm{g} \mathrm{g}^{-1}$ dry weight to 11.18 and $195.62 \mu \mathrm{g} \mathrm{g}^{-1}$ dry weight in cultures exposed to iron-nano oxide. The cell cultures treated with zinc- and iron- oxide nanoparticles showed enhanced hyperforin content as compared to the hypericin production. It can be suggested that nanoparticles can be appropriate candidates for elicitation of in vitro secondary metabolite production. Jasmonate, an important stress hormone, triggered various plant defense responses, along with the biosynthesis of defensive secondary metabolites [77]. Nanoparticles may play an important role in regulating the expression of genes for jasmonate production in treated cells. Induced jasmonate production may be responsible for enhanced production of hypericin and hyperforin. Studies on the uptake mechanism, transportation, and binding sites of nanoparticles in plant cells are required to elucidate the elicitation mechanism of these in vitro applied nanoparticles for the enhancement of secondary metabolite production. However, higher concentrations of zinc- and iron-nano oxides (150 ppb) showed adverse effects on hypericin and hyperforin production [18].

Enhancement of flavonoids and isoflavonoids are the most popular groups of secondary metabolites found in plants. Many legume seeds have been reported to be rich sources of these secondary metabolites [78]. AL-Oubaidi and Kasid (2015) demonstrated the increased production of secondary metabolite (phenolic and flavonoid compounds) in gram on exposure to $\mathrm{TiO}_{2} \mathrm{NPs}$ under in vitro condition. Secondary metabolite contents in the callus were estimated qualitatively and quantitatively using HPLC and compared with the mother plant. $\mathrm{TiO}_{2} \mathrm{NPs}$ at varying concentrations $(0.5,1.5,3,4.5,6)$ $\mathrm{mg} \mathrm{L}^{-1}$ were used for an effective increase in secondary metabolites [79]. The results revealed that the secondary metabolite concentration from callus embryo of gram increased to highly significant level at the concentrations of 4.5 and $6.0 \mathrm{mg} \mathrm{L}^{-1}$. The HPLC outcomes confirmed the elevation in the secondary metabolite level under the effect of the $\mathrm{TiO}_{2} \mathrm{NPs}$ when compared with the mother plant. In a very recent report, Khan et al. (2016) examined the effect of nine types of metal NPs including monometallic and bimetallic alloy nanoparticles [Ag, $\mathrm{Au}, \mathrm{Cu}$, $\mathrm{AgCu}$ (1:3), $\mathrm{AgCu}$ (3:1), $\mathrm{AuCu}$ (1:3), $\mathrm{AuCu}$ (3:1), $\mathrm{AgAu}(1: 3), \quad \mathrm{AgAu}(3: 1)]$ on total phenolic and flavonoid contents in milk thistle plant. The sterilized seeds were soaked in NPs suspensions for $2 \mathrm{~h}$ and allowed to grow under in vitro condition [80]. The experiment was conducted for 6 weeks, and samples for total phenolic and flavonoid contents were collected on weekly interval. Nanomaterials suspensions affected total phenolic and flavonoid contents in the plant in a different way. It was observed that the amount of phenolics and flavonoids did not show any correlation with the total dry mass of the plant. However, duration of the experiment significantly affected the amount of total flavonoids and phenolics in milk thistle. After 21 days presoaking of seeds in

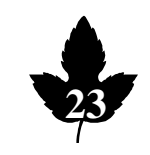


bimetallic alloy, enhanced whereas monometallic nanoparticles suspensions, reduced phenolics and flavonoids content in milk thistle plantlets. After 28 days, $\mathrm{Au}$ and $\mathrm{Cu}$ nanoparticles caused maximum total phenolic and flavonoid accumulation in milk thistle plants. Therefore, maximum effect on secondary metabolites was recorded with monomatellic nanoparticles. Mainly three factors (size, surface area, and composition of nanoparticles) played a significant role either singly or in combination.

Recently, the effects of multi-walled carbon nanotubes (MWCNTs, 5-15 nm) were studied on callus induction and biosynthesis of secondary metabolites in Satureja khuzestanica grown in vitro [81]. In the Gamborg's B-5 (B5) medium, various MWCNTs concentrations (0, 25, 50, 100, 250 and $500 \mu \mathrm{g} / \mathrm{mL}$ ) were used. The authors reported enhanced total flavonoids content of callus extracts upon exposure to all concentrations. However, total phenolics content began to increase at lower MWCNTs exposure levels. After 15 days of exposure at $100 \mu \mathrm{g} / \mathrm{mL}$ both total flavonoids and phenolics contents were peaked by 2.6 and 1.9 folds, respectively, as compared to control. Moreover, $100 \mu \mathrm{g} / \mathrm{mL}$ MWCNTs exposure significantly enhanced two main phenolic acids (rosmarinic acid and caffeic acid) contents compared to other treatments.

In another study, Ghorbanpour (2015) evaluated the influence of $\mathrm{TiO}_{2} \mathrm{NPs}$ on a medicinal plant Salvia officinalis. The plants were foliar sprayed with various doses of $\mathrm{TiO}_{2} \mathrm{NPs}(0,10,50,100,200$ and $1000 \mathrm{mg} / \mathrm{L})$. Upon exposure, $\mathrm{TiO}_{2}$ NPs significantly improved total leaf phenolics and flavonoids contents of the plant compared to control. However, the extract yield (\% w/w) was not significantly changed between employed treatments [24]. Similarly, Oloumi et al. (2015) showed that in agar growth medium containing Hoagland nutrient solution, 1 and $10 \mu \mathrm{M} \mathrm{CuO}$ and $\mathrm{ZnO}$ nano particles exposure on Glycyrrhiza glabra seedlings enhanced the phenolic compounds and glycyrrhizin content as compared to their bulk counterpart [82]. There have been many other reports of plant phenolics [83] and flavonoids [84] production upon abiotic elicitors exposure. The reports on the extract yields following exposure to $\mathrm{TiO}_{2} \mathrm{NPs}$ in Salvia officinalis are to some extent ambiguous, possibly because of the fact that extraction yield of plant raw materials depends on different methodological factors such as extraction solvent type (methanol, ethanol, acetone and water) and extraction time and so on [85]. It has been reported that the leaf extract of $S$. officinalis plant exposed to $\mathrm{TiO}_{2} \mathrm{NPs}$ at $200 \mathrm{mg} / \mathrm{L}$ showed strong antioxidant activity (lower $\mathrm{IC}_{50}$ value), when compared to untreated controls and BHT [24]. A positive relationship exists between phenolic and flavonoid compounds and antioxidant activity potential. Therefore, phenolics protect plants against oxidative damage by reducing ROS toxicity on cellular components $[86,87]$.

\section{Gum, resin, and saponin}

Significant enhancement in the gum content and its viscosity was reported in cluster bean seeds when the leaf of plant was foliar-sprayed with $\mathrm{ZnONPs}$ at $10 \mathrm{mg} \mathrm{L}^{-1}$ [88]. Increased 
growth traits and gum content might be due to adsorption of nanoparticles on plant surface and taken up by the plants via natural nano or microscale openings and or stomata [88]. The effects of AgNPs and methyl jasmonate (MeJA) on secondary metabolites of marigold were studied [20]. The authors reported that plants exposed to AgNPs showed decreased chlorophyll and carotenoid contents by 30$50 \%$, while MeJA treated plants increased both of these contents, whereas when plants were treated with $0.4 \mathrm{mM}$ SNPs and $100 \mu \mathrm{M}$ MeJA, saponin content in the plants improved up to $177 \%$. Significant decrease in the viability of HeLa cells was noted when exposed to the extracts of marigold, and this reduction was more evident in the plants exposed to MeJA and AgNPs. Kole et al. (2013) observed varied impacts of seed treatment with five doses of fullerol on the content of five phytomedicines in bitter melon fruits. The contents of two anticancer phytomedicines, namely cucurbitacin $\mathrm{B}$ and lycopene, were increased by 74 and $82 \%$, at 9.88 and $47.2 \mathrm{nM}$ fullerol treatments, respectively. Antidiabetic phytomedicines, charantin, and insulin contents were improved by 20 and $91 \%$, when the seeds were treated with 4.72 and $9.88 \mathrm{nM}$ fullerol, respectively [89].

Several strategies have been carried out to enhance the yields of secondary metabolites also known as natural products or phytochemicals in medicinal plants. Only few studies reported the improvement of secondary metabolites on treatment with nanomaterials under in vivo condition, whereas the effects of different nanomaterials have been reported on plant growth and metabolic function [90, 74]. The same concentration of individual nanomaterials may cause effects in diverse directions and ranges on different variables. Therefore, selection of the best concentration of nanoparticles is essential for identifying higher benefits for a target agro-economic trait.

\section{Potential mechanisms involved in elicitation of plant secondary metabolism by nanomaterials}

The direct biophysical and/or biochemical interactions at the nanoparticles-biological interfaces/systems are not yet widely known. However, it has been suggested that carbonaceous nanomaterials adsorb on cell surfaces mainly through hydrophobic, electrostatic, receptor-ligand and hydrogen bonding interactions [34]. Carbon-based nanomaterials also form envelop at the surface of cells and make clusters with filamentous structures and enter the plant cell wall [91], leading to changes in metabolic processes. Exposure of plant cell culture to elicitors induces transduction cascades, resulting in expression of different genes encoding enzymes involved in activation of secondary metabolites biosynthesis [91].

Ghorbanpour and Hadian (2015) noted that changes in biosynthesis of secondary metabolites upon MWCNTs exposure could be related to specific activities of different enzymes such as phenylalanine ammonia lyase (PAL), peroxidase (POD) and polyphenol oxidase (PPO). They found that enhanced biosynthesis and accumulation of total phenolics upon exposure to MWCNTs (at 100 
and $250 \mu \mathrm{g} / \mathrm{mL}$ ) was positively correlated to PAL activity [81]. Similarly, an increase in PAL activity has been reported to be coupled with production of total phenolics in in vitro culture [92]. Khodakovskaya et al. (2011) reported that carbon-based nanomaterials may up-regulate multiple genes involved in stress signaling cascades and trigger a molecular pattern that is similar to plant response against biotic stresses such as insects, herbivores or pathogens attack [93]. A schematic model for nanomaterials exposure-induced biosynthesis of secondary metabolites is presented in Figure 4.

Overproduction of ROS including superoxide $\left(\mathrm{O}^{2-}\right)$, hydroxyl radical $\left(\mathrm{OH}^{-}\right)$and hydrogen peroxide $\left(\mathrm{H}_{2} \mathrm{O}_{2}\right)$ in plant cells following exposure to nanomaterials can be another possible mechanism for increasing the production of secondary metabolites. The rapid and extra generation of $\mathrm{H}_{2} \mathrm{O}_{2}$, which is known as oxidative burst regulates enzymatic and non-enzymatic antioxidant defense systems in plants in response to various biotic and abiotic stresses [94].

According to Jabs et al (1997), generation of $\mathrm{H}_{2} \mathrm{O}_{2}$ may change redox status of the plant cells, and act as a signaling molecule for triggering biosynthesis pathways of secondary metabolites [95]. The content of several types of secondary metabolites such as phenolics, flavonoids, rosmarinic acid and caffeic acid were shown to rise following the increased $\mathrm{H}_{2} \mathrm{O}_{2}$ level caused by application of high concentrations of MWCNTs [81]. A regulation of anthraquinone biosynthesis was observed with increasing $\mathrm{H}_{2} \mathrm{O}_{2}$ content in cell suspension culture of Morinda elliptica [96].
Likewise, Zhang et al. (2013) reported enhancement of artemisinin biosynthesis from treatment with Ag NPs that significantly correlated to the overproduction of free radicals (ROS) [19].

Although the aforesaid reports indicate that nanoparticles are interacting with different signaling cascades and able to modulate plant secondary metabolism, the exact mechanism through which this modulation could take place is not yet well known. It has been established that the initial responses of plants exposed to nanoparticles might include increased levels of ROS, cytoplasmic $\mathrm{Ca}_{2} \mathrm{C}$ and activation of mitogen-activated protein kinase (MAPK) cascades the same as biotic/abiotic stresses (Figure 6) due to the following reasons.

It has been reported that recognition of $\mathrm{Ag}$ NPs by plasma membrane bound receptors in A. thaliana triggered $\mathrm{Ca}_{2} \mathrm{C}$ burst and $\mathrm{ROS}$ induction [98]. The levels of $\mathrm{Ca}_{2} \mathrm{C}$ and related signaling pathway proteins were up-regulated in O. sativa roots treated with $\mathrm{Ag} \mathrm{NP}$ in a proteomic analysis [99]. It has been hypothesized that Ag NPs, or their released ions, prevent cell metabolism following binding to $\mathrm{Ca}_{2} \mathrm{C}$ receptors, $\mathrm{Ca}_{2} \mathrm{C}$ channels, $\mathrm{Ca}_{2} \mathrm{C} / \mathrm{NaC}$ ATPases of plasma membrane [99]. As sensed by $\mathrm{Ca}^{2+}$-binding proteins or other NP-specific proteins, NPs either mimic $\mathrm{Ca}_{2} \mathrm{C}$ or act as signaling molecules in the cytosol [100]. MAPK phosphorylation events and activation of downstream transcription factors mainly caused to the transcriptional reprogramming of secondary metabolism in 


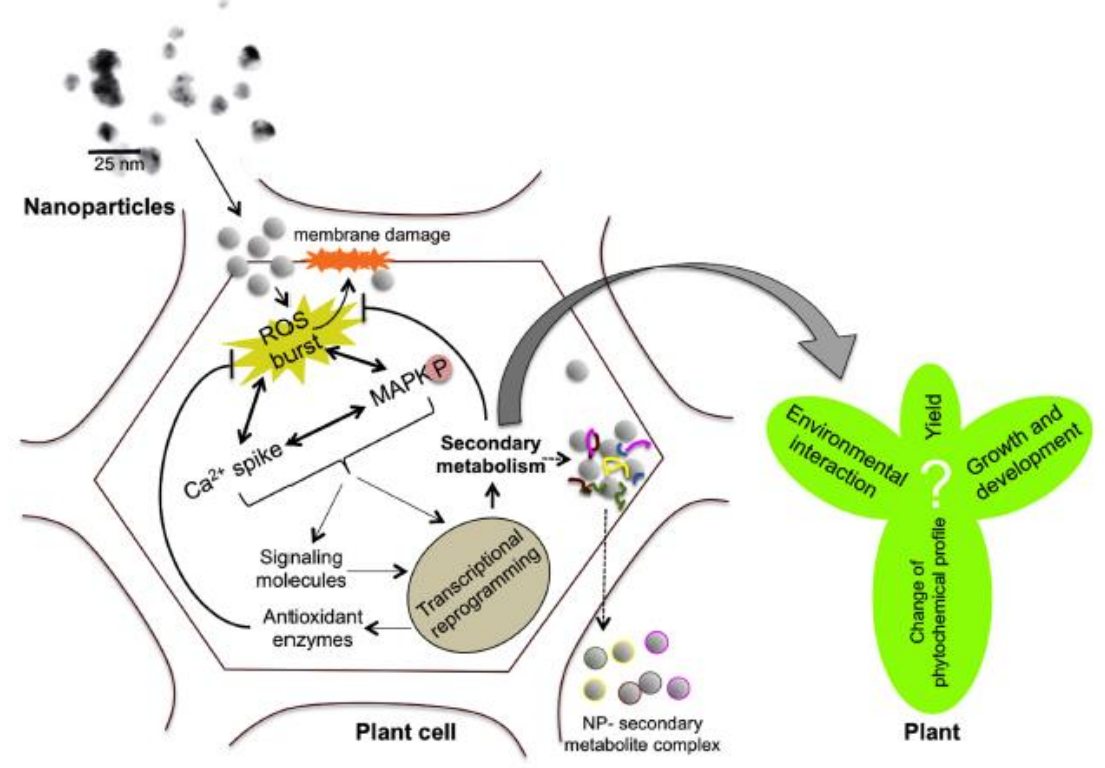

Figure 6- The possible mechanisms involved in plant cell elicitation of secondary metabolites exposed to nanoparticle (NP). NPs may induce generation of reactive oxygen species (ROS) through interaction with cells both on the cell surface and/or within cells. Cellular signaling machineries such as calcium spikes, antioxidant systems and mitogenactivated protein kinase (MAPK) cascades, etc., trigger extensive transcriptional reprogramming of gene expression involved in secondary metabolism [97].

plant cells [101-103]. Until the present time, no direct evidence is available regarding involvement of MAPK pathways in plant-NPs interactions; however, animal and human cell line researches showed that similar pathways are involved in Ag NP-induced signaling [104, 105]. Therefore, it has been presumed that plants may also utilize MAPK cascade following exposure to Ag NPs [106].

\section{Conclusions and future perspectives}

Manufactured nanomaterials (with a size ranging 1-100 $\mathrm{nm}$ in at least one dimension) have acquired significant interest and concern in recent years, and produced for various applications such as medicine, chemistry, biology, electronics, environment, textiles, energy storage, food science and plant production/protection.
Plants are a rich source of various natural bioactive secondary metabolites, which play as phytoalexins/and or phytoanticipins in the survival of plants in their respective environments from different types of biotic and abiotic stresses [107]. The interaction between plant cells and manufactured nanomaterials is very complex and depends on both nanomaterial characteristics (e.g., concentration, size, shape, surface features, and crystal chemistry) and plant traits (e.g., genotype and age) as well as time and route of exposure, etc. From the systematic review of published literature, it can be concluded that exposure to manufactured nanoscale materials has the potential to change the plant secondary metabolism. The content of secondary metabolites in plant cell was remarkably improved by optimizing the composition of the 
culture medium, incorporation of precursors and elicitors and providing suitable culture conditions. nanoparticles supplemented to the plant culture medium may act as a nutrient source and an elicitor. Besides, they also serve as physical and chemical barriers to abiotic stressors and as potential antioxidants to scavenge ROS [108, 109]. Furthermore, the presence of nanomaterials in the environmental matrices substantially affect the pharmacological characteristics of medicinal and aromatic plants, as many phytomedicines exert their beneficial impacts via additive or synergistic roles of many compounds acting on single- and multi-target sites related to the physiological process [110]. Nanomaterialmediated changes in plant secondary

\section{References}

1. Buzea C, Pacheco I and Robbie K. Nanomaterials and nanoparticles: sources and toxicity. Biointerphases 2007; 2: Mr17-Mr71.

2. Buzea $C$ and Pacheco I. Nanomaterial and Nanoparticle: Origin and Activity, In: Nanoscience and Plant-Soil Systems, M. Ghorbanpour et al. (eds.), Soil Biology, 2017, 48, DOI 10.1007/978-3-319-46835-8_3.

3. Scrinis G, Lyons K. The emerging nanocorporate paradigm: nanotechnology and the transformation of nature, food and agri-food systems. Int. J. Soc. Agric. Food 2007; 15: 22-44. 4. Dallavalle M, Calvaresi M, Bottoni A, Melle-Franco $M$ and Francesco-Zerbetto F. Graphene Can Wreak Havoc with Cell Membranes. ACS Appl. Mater. Interfaces 2015; 7 (7): 4406-4414.

5. Hu X, Zhou M and Zhou Q. Ambient Water and Visible-Light Irradiation Drive Changes in Graphene Morphology, Structure, Surface metabolism could also be beneficial if harnessed in such a way that nanomaterials are used as elicitors/precursors in biotechnology to improve the production of medicinally active ingredients [19, 111, 120-124]. However, researches in the large-scale field or field-like conditions are necessary to achieve a more realistic understanding of the potential effects of nanomaterials on key biotic and abiotic properties of the ecosystems involved, which consequently may have a deep effect on human health. Moreover, previous studies have widely used agricultural and horticultural crops, while research on medicinal and aromatic plants is quite recent and these less-considered plants require a more consideration due to their valuable pharmaceutically properties.
Chemistry, Aggregation, and Toxicity. Environ. Sci. Technol. 2015; 49 (6): 3410-3418.

6. Ghorbanpour M and Hadian J. Engineered Nanomaterials and Their Interactions with Plant Cells: Injury Indices and Detoxification Pathways. M. Ghorbanpour et al. (eds.), Nanoscience and Plant-Soil Systems, Soil Biology 2017; 48: DOI 10.1007/978-3-31946835-8_13.

7. Hatami, M, Kariman $\mathrm{K}$ and Ghorbanpour M. Engineered nanomaterial-mediated changes in the metabolism of terrestrial plants. Science of the Total Environment 2016; 571: 275-291. 8. Sun T, Zhang YS, Pang B, Hyun DC, Yang $\mathrm{M}$ and Xia Y. Engineered nanoparticles for drugdelivery in cancer therapy. Angew. Chem. Int. Ed. Engl. 2014; 53 (46): 12320-64.

9. Hartmann T. From waste products to ecochemicals: fifty years research of plant 
secondarymetabolism. Phytochemistry 2007; 68: 2831-2846.

10. Ncube B and Van Staden J. Tilting Plant Metabolism for Improved Metabolite Biosynthesis and Enhanced Human Benefit. Molecules 2015; 20 (7): 12698-12731.

11. Zhao DX, Fu CX, Han YS and Lu DP. Effects of elicitation on jaceosidin and hispidulinproduction in cell suspension cultures of Saussurea medusa. Process Biochem. 2005a; 40 (2): 739-745.

12. Zhao J, Davis LC and Verpoorte R. Elicitor signal transduction leading to production ofsecondary metabolites. Biotechnol. Adv. 2005b; 23: 283-333.

13. Rao SR and Ravishankar GA. Plant cell cultures: chemical factories of secondary metabolites. Biotechnol. Adv. 2002; 20: 101-153.

14. Mulabagal V and Tsay HS. Plant cell cultures-an alternative and efficient source for theproduction of biologically important secondary metabolites. Int. J. Appl. Sci. Eng. 2004; 2: 29-48.

15. Fakruddin MD, Hossain $\mathrm{Z}$ and Afroz $\mathrm{H}$. Prospects and applications of nanobiotechnology: amedical perspective. $J$. Nanobiotechnol. 2012; 10: 1-8.

16. Aditya N, Patnakar S, Madhusudan B, Murthy R and Souto E. Artemether loaded lipidnanoparticles produced by modified thin film hydration: pharmacokinetics, toxicological andinvivo antimalarial activity. Eur. J. Pharm. Sci. 2010; 40: 448-455.

17. Asghari GH, Mostajeran A, Sadeghi H and Nakhaei A. Effect of salicylic acid and silver nitrateon taxol production in Taxus baccata. $J$. Med. Plants 2012; 11 (8): 74-82.
18. Sharafi E, Nekoei SMK, Fotokian MH, Davoodi D, Mirzaei $\mathrm{HH}$ and Hasanloo $\mathrm{T}$. Improvementof hypericin and hyperforin production using zinc and iron nano-oxides as elicitors in cellsuspension culture of St John's wort (Hypericum perforatum L.). J. Med. Plants By-prod 2013; 2: 177-184.

19. Zhang B, Zheng L.P, Yi Li W and Wen Wang J. Stimulation of artemisinin production in Artemisia annua hairy roots by $\mathrm{Ag}-\mathrm{SiO} 2$ core-shell nanoparticles. Curr. Nanosci. 2013; 9: 363-370.

20. Ghanati $F$ and Bakhtiarian S. Effect of methyl jasmonate and silver nanoparticles on production of secondary metabolites by Calendula officinalis L. (Asteraceae). Trop. J. Pharmaceut. Res. 2014; 13 (11): 1783-1789.

21. Hatami M and Ghorbanpour M. Defense enzymes activity and biochemical variations of Pelargonium zonale in response to nanosilver particles and dark storage. Turk. J. Biol. 2014; 38: 130-139.

22. Raei M, Angaji SA, Omidi $M$ and Khodayari M. Effect of abiotic elicitors on tissue culture of Aloe vera. Int. J. Biosci. 2014; 5 (1): 74-81.

23. Ghasemi B, Hosseini R and Nayeri FD. Effects of cobalt nanoparticles on artemisininproduction and gene expression in Artemisia annua. Turk. J. Bot. 2015; 39: 769 - 777.

24. Ghorbanpour M. Major essential oil constituents, total phenolics and flavonoids content and antioxidant activity of Salvia officinalis plant in response to nano-titanium dioxide. Ind. J. Plant Physiol. 2015; 20 (3): 249-256.

25. Yarizade K, Hosseini R. Expression analysis of ADS, DBR2, ALDH1 and SQS genes in Artemisia vulgaris hairy root culture 
under nano cobalt and nano zinc elicitation. Ext. J. App. Sci. 2015; 3 (3): 69-76.

26. Baiazidi-Aghdam MT, Mohammadi $H$ and Ghorbanpour M. Effects of nanoparticulate anatase titanium dioxide on physiological and biochemical performance of Linum usitatissimum (Linaceae) under well watered and drought stress conditions. Braz. J. Bot. 2016; 39: 139-146.

27. Yadav T, Mungray A.A and Mungray A.K. Fabricated Nanoparticles: Current Status and Potential Phytotoxic Threats. In: WHITACRE,

D. M. (ed.) Reviews of Environmental Contamination and Toxicology. Springer Verlag, Switzerland. 2014; 230: 83-110.

28. Ma C.X, White J.C, Dhankher O.P and Xing B. Metal-based Nanotoxicity and Detoxification Pathways in Higher Pplants. Environ. Sci. Technol. 2015; 49 (12): 7109-7122.

29. Deng Y.Q, White J.C and Xing, B.S. Interactions Between Engineered Nanomaterials and Agricultural Crops: Implications for Food Safety. Journal of Zhejiang University-Science A 2014; 15: 552-572.

30. Fleischer A, O’Neill M.A and Ehwald R. The Pore size of Non-graminaceous Plant Cell Walls is Rapidly Decreased by Borate Ester Cross-linking of the Pectic Polysaccharide Rhamnogalacturonan II. Plant Physiol. 1999; 121: 829 - 838 .

31. Lin S, Reppert J, Hu Q, Hudson J.S, Reid M.L, Ratnikova T.A, Rao A.M, Luo H and Ke P.C. Uptake, Translocation, and Transmission of Carbon Nanomaterials in Rice Plants. Small 2009; 5: 1128-1132.

32. Rico C.M., Majumdar S., Duarte-Gardea M., Peralta-Videa, J.R. and Gardea-Torresdey J.L. Interaction of nanoparticles with edible plants and their possible implications in the food chain. J. Agric. Food Chem. 2011; 59: 3485 - 3498.

33. Wild E and Jones K.C. Novel Method for the Direct Visualization of in vivoNanomaterials and Chemical Interactions in Plants. Environ. Sci. Technol. 2009; 43; 5290-5294.

34. Nel A.E, Madler L, Velegol D, Xia T, Hoek E.M.V., Somasundaran P, Klaessig F, Castranova $\mathrm{V}$ and Thompson $\mathrm{M}$. Understanding Biophysicochemical Interactions at the Nano-bio Interface. Nat. Mater. 2009; 8 (7): 543-557.

35. Saptarshi Shruti R, Albert Duschl and Andreas L Lopata. Interaction of nanoparticles with proteins: relation to bio-reactivity of the nanoparticle. J. Nanobiotechnol. 2013; 11: 26.

36. Wang S.H, Kurepa J and Smalee J.A. Ultra-small $\mathrm{TiO}_{2}$ Nanoparticles Disrupt Microtubular Networks in Arabidopsis thaliana. Plant Cell and Environment 2011; 34: 811-820.

37. Larue C, Castillo-Michel H, Sobanska S, Cecillon L, Bureau S, Barthes V, Ouerdane L, Carriere $\mathrm{M}$ and Sarret G. Foliar Exposure of the Crop Lactuca sativa to Silver Nanoparticles: Evidence for Internalization and Changes in Ag speciation. J. Hazard. Mater. 2014a; 264: 98-106.

38. Larue C, Castillo-Michel H, Sobanska S, Trcera N, Sorieul S, Cecillon L, Ouerdanef L, Legrosg S and Sarreta G. Fate of Pristine $\mathrm{TiO}_{2}$ Nanoparticlesand Aged Paint-Containing $\mathrm{TiO}_{2}$ Nanoparticles in Lettuce Crop after FoliarExposure. J. Hazard. Mater. 2014b; 273: 17-26.

39. Hong J, Peralta-Videa J.R, Rico C, Sahi S, Viveros M.N, Bartonjo J, Zhao L.J and Gardea-Torresdey J.L. Evidence of 
Translocation and Physiological Impactsof Foliar Applied $\mathrm{CeO}_{2}$ Nanoparticles on Cucumber (Cucumis sativus) Plants. Environ. Sci. Technol. 2014; 48: 4376-4385.

40. Etxeberria E, Gonzalez $\mathrm{P}$ and Pozueta J. Evidence for Two Endocytic Ttransport Pathways in Plant Cells. Plant Sci. 2009; 177 (4): 341 - 348.

41. Ovecka M, Lang I, Baluska F, Ismail A, Illes $\mathrm{P}$ and Lichtscheidl I.K. Endocytosis and Vesicle Trafficking during Tip Growth of Root Hairs. Protoplasma 2005; 226 (1): 39 - 54.

42. Perez-de-Luque A. Interaction of Nanomaterials with Plants: What Do We Need for Real Applications in Agriculture? Frontiers in Environmental Sci. 2017; 5: 1-7.

43. Ma X, Wang Q, Rossi L and Zhang W. Cerium Oxide Nanoparticles and Bulk Cerium Oxide Leading to Different Physiological and Biochemical Responses in Brassica rapa. Environ. Sci. Technol. 2015; DOI: 10.1021/acs.est.5b04111.

44. Zahed H, Ghazala M and Setsuko K. Plant Responses to Nanoparticle Stress. International Journal of Molecular Science 2015; 16: 26644-26653.

45. Hatami M. Toxicity assessment of multiwalled carbon nanotubes on Cucurbita pepo L. under well-watered and water-stressed conditions. Ecotoxicology and Environmental Safety 2017a; 142: 274-283.

46. Hatami M. Stimulatory and Inhibitory Effects of Nanoparticulates on Seed Germination and Seedling Vigor Indices. M. Ghorbanpour et al. (eds.), Nanoscience and Plant-Soil Systems, Soil Biology 2017b, 48: DOI 10.1007/978-3-319-46835-8_13.
47. Hatami M, Hadian J and Ghorbanpour M. Mechanisms underlying toxicity and stimulatory role of single-walled carbon nanotubes in Hyoscyamus niger during drought stress simulated by polyethylene glycol. J. Hazard. Mater. 2017; 324: 306-320. 48. Yang J, Cao $\mathrm{W}$ and Rui $\mathrm{Y}$. Interactions between nanoparticles and plants: phytotoxicity and defense mechanisms. Journal of Plant Interactions 2017; 12: 158 - 169.

49. Schwab F., Zhai G., Kern M., Turner A., Schnoor J.L. and Wiesner M.R. Barriers, pathways and processes for uptake, translocation and accumulation of nanomaterials in plants-Critical review. Nanotoxicol. 2015; 10: 257-278.

50. Etxeberria E., Gonzalez P., BarojaFernandez E. and Romero J.P. Fluid phase endocytic uptake of artificial nano-spheres and fluorescent quantum dots by sycamore cultured cells: evidence for the distribution of solutes to different intracellular compartments. Plant Signal. Behav. 2006; 1: 196-200.

51. Wong M.H., Misra R.P., Giraldo J.P., Kwak S.OY., Son Y., Landry M.P. and et al. Lipid exchange envelope penetration (LEEP) of nanoparticles for plant engineering: a universal localization mechanism. Nano Lett. 2016; 16: 1161 - 1172.

52. Serag M.F., Kaji N., Gaillard C., Okamoto Y., Terasaka K., Jabasini M. and et al. Trafficking and subcellular localization of multiwalled carbon nanotubes in plant cells. ACS Nano 2011; 5: 493 - 499.

53. Wu B. and Beitz E. Aquaporins with selectivity for unconventional permeants. Cell. Mol. Life Sci. 2007; 64: 2413 - 2421. 
54. Roberts A.G. and Oparka K.J. Plasmodesmata and the control of symplastic transport. Plant Cell Environ. 2003; 26: 103-124.

55. Zhai G., Walters K.S., Peate D.W., Alvarez P.J. and Schnoor J.L. Transport of gold nanoparticles through plasmodesmata and precipitation of gold ions in woody poplar. Environ. Sci. Technol. Lett. 2014; 1: 146 - 151.

56. Rispail N., De Matteis L., Santos R., Miguel A.S., Custardoy L., Testillano P. and et al. Quantum dots and superparamagnetic nanoparticles interaction with pathogenic fungi: internalization and toxicity profile. ACS Appl. Mater. Interfaces 2014; 6: 9100-9110.

57. Ghorbanpour $M$, Hatami $M$ and Hatami M. Activating antioxidant enzymes, hyoscyamine and scopolamine biosynthesis of Hyoscyamus niger L. plants with nano-sized titanium dioxide and bulk application. Acta Agric. Slov. 2015; 105: 23-32.

58. Jamshidi $M$. and Ghanati F. Taxanes content and cytotoxicity of hazel cells extract after elicitation with silver nanoparticles. Plant Physiol. Biochem. 2017; 110: 178-184.

59. Amuamuha L, Pirzad A and Hadi $H$. Effect of varying concentrations and time of nanoironfoliar application on the yield and essential oil of Pot marigold. Int. Res. J. Appl. Basic. Sci. 2012; 3: 2085 - 2090.

60. Ferreira JFS, Simon JE and Janick J. Developmental studies of Artemisia annua: flowering andartemisinin production under greenhouse and field conditions. Planta Med. 1995; 61: 167 - 170.

61. Baldi A and Dixit VK. Yield enhancement strategies for artemisinin production by suspensionculture of Artemisia annua. Bioresour. Technol. 2008; 99: 4609 - 4614.
62. Bahreini M, Omidi M, Bondarian F and Gholibaygian M. Metabolites screening of nanoelicited in vitro Iranian fennel (Foeniculum vulgare). Am. J. Biol. Life Sci. 2015; 3 (5): 194-198.

63. Billia AR, Flamini G, Tagioli V, Morelli I and Vincieri FF. GC-MS analysis of essential oil ofsome commercial Fennel teas. Food Chem. 2002; 76 (3): 307 - 310.

64. Gurdip S, Maurya S, de Lampasona MP and Catalan C. Chemical constituents, antifungal andantioxidative potential of Foeniculum vulgare volatile oil and its acetone extract. Food Control 2006; 17: 745 - 752.

65. Chaouche $\mathrm{T}$, Haddouchi $\mathrm{F}$, Lazouni HA and Bekkara FA. Phytochemical study of the plant Foeniculum vulgare Mill. Pharm. Lett. 2011; 3 (2): 329 - 333.

66. Aghajani Z., Pourmeidani A. and Ekhtiyari R. Effect of Nano-silver on Stages of Plant Growth and Yield and Composition of Essential of Thymus kotchyanus Boiss. \& Hohen. Afr. J. Agric. Res. 2013; 8: 707 - 710.

67. Ghorbanpour $M$ and Hatami H. Changes in growth, antioxidant defense system and major essential oils constituents of Pelargonium graveolens plant exposed to nano-scale silver and thidiazuron. Ind. J. Plant Physiol. 2015; 20 (2): 116 - 123.

68. Bakkali F., Averbeck S., Averbeck D. and Idaomar M. Biological Effects of Essential Oils. Rev. Food Chem. Toxicol. 2008; 46: 446 - 475.

69. Ram P., Kumar B., Naqvi A.A., Verma R.S. and Patra N.K. Post-harvest Storage Effect on Quality and Quantity of Rosescented Geranium [Pelargonium sp. cv. Bourbon] Oil in Uttarancha. Flavour Fragr. J. 2005; 20: 666 - 668. 
70. Swamy K.N. and Rao S.S.R. Effect of 24epibrassinolide on Growth, Photosynthesis, and Essential oil Content of Pelargonium graveolens L. Herit. Russ. J. Plant Physl. 2009; 56: 616-620.

71. Osawa T. Novel Natural Antioxidants for Utilization in Food and Biological Systems, in: I. Uritani, V.V. Garcia, E.M. Mendoza (Eds.), Postharvest Biochemistry of Plant Food-Materials in the Tropics, Japan Scientific Societies Press, Tokyo, Japan, 1994, pp: 241-251.

72. Reynolds T. Aloe chemistry. In: Reynolds $\mathrm{T}$ (ed) The genus Aloe. CRC Press, Boca Raton, 2004, pp: 39-74.

73. Hasanuzzaman $\mathrm{M}$, Ahamed KU, Khalequzzaman KM, Shamsuzzaman AMM, Nahar K Plant characteristics, growth and leaf yield of Aloe vera L. as affected by organic manure in potculture. Aust. J. Crop Sci. 2008; 2 (3): 158 - 163.

74. Krishnaraj C, Jagan EG, Ramachandran R, Abirami SM, Mohan N, Kalaichelvan PT. Effect of biologically synthesized silver nanoparticles on Bacopa monnieri (Linn.) Wettst. plantgrowth metabolism. Process Biochem. 2012; 47:651-658.

75. Deltito J and Beyer D. The scientific, quasiscientific and popular literature on the use of St.John's Wort in the treatment of depression. $J$. Affect. Disord. 1998; 51: 245 -251.

76. Dias ACP, Tomas-Barberan FA, Fernandes-Ferreira $\mathrm{M}$ and Ferreas $\mathrm{F}$ Unusual flavonoidsproduced by callus cultures of Hypericum perforatum. Phytochemistry 1998; 48: 1156 - 1168.

77. Menke F, Champion A, Kijne $J$ and Memelink J. A novel jasmonate- and elicitorresponsiveelement in the periwinkle secondary metabolite biosynthetic gene Str interacts with a jasmonateand elicitor-inducible AP2-domain transcription factor, ORCA2. Eur. Mol. Biol. Org. 2009; 18: 4455 - 4463.

78. Heiras-Palazuelos MJ, Ochoa-Lugo MI, Gutierrez-Dorado R, Lopez Valenzuela JA, MoraRochin S, Milan Carrillo J and et al Technological properties, antioxidant activity and total phenolicand flavonoid content of pigmented chickpea (Cicer arietinum L.) cultivars. Int. J. Food Sci. Nutr. 2013; 64: 69 -76.

79. AL-Oubaidi HKM and Kasid NM. Increasing (phenolyic and flavonoids compounds of Cicer arietinum L. from embryo explant using titanium dioxide nanoparticle in vitro. World J. Pharmaceut. Res. 2015; 4 (11): 1791-1799.

80. Khan MS, Zaka M, Abbasi BH, Rahman LU and Shah A. Seed germination and biochemicalprofile of Silybum marianum exposed to monometallic and bimetallic alloy nanoparticles. IET Nanobiotechnol. 2016 doi:10.1049/iet-nbt.2015.0050.

81. Ghorbanpour $M$ and Hadian J. Multiwalled carbon nanotubes stimulate callus induction, secondary metabolites biosynthesis and antioxidant capacity in medicinal plant Satureja khuzestanica grown in vitro. Carbon 2015; 94: 749 - 759.

82. Oloumi H., Soltaninejad R. and Baghizadeh A. The Comparative Effects of Nano and Bulk Size Particles of $\mathrm{CuO}$ and $\mathrm{ZnO}$ on Glycyrrhizin and Phenolic Compounds Contents in Glycyrrhiza glabra L. Seedlings. Ind. J. Plant Physiol. 2015; 20: 157 - 161.

83. Diaz J.G., Bernal A., Pomar F. and Merino F. Induction of Shikimate Dehydrogenase and Peroxidase in Pepper (Capsicum annum L.) 
Seedlings in Response to Copper Stress and its Relation to Lignification. J. Plant Sci. 2001; 161: 179 - 188.

84. Cristina B. and Constantin D. The Effect of Copper Sulphate on the Production of Flavonoids in Digitalis Lanata Cell cultures. Farmacia 2011; 59: 113-118.

85. Shimada K., Fujikawa K., Yahara K. and Nakamura T. Antioxidative Properties of Xanthone on the Auto-oxidation of Soybean in Cylcodextrin Emulsion. J. Agr. Food Chem. 1992; 40: 945 - 948.

86. Mittler R. Oxidative Stress, Antioxidants and Stress Tolerance. Trends Plant Sci. 2002; 7 (9): 405-410.

87. Li H.B., Wong C.C., Cheng K.W. and Chen F. Antioxidant Properties in vitro and Total Phenolic Contents in Ethanol Extracts from Medicinal Plants. LWT-Food Science and Technology 2008; 41: 385 - 390.

88. Raliya $\mathrm{R}$ and Tarafdar JC. $\mathrm{ZnO}$ nanoparticle biosynthesis and its effect on phosphorousmobilizingenzyme secretion and gum contents in cluster bean (Cyamopsis tetragonoloba L.). Agric. Res. 2013; 2 (1): 48 -57.

89. Kole C, Kole P, Randunu KM, Choudhary P, Podila R and Ke PC. Nanobiotechnology canboost crop production and quality: first evidence from increased plant biomass, fruit yield andphytomedicine content in bitter melon (Momordica charantia). BMC Biotechnol. 2013; 13: 37.

90. Nair R, Varghese SH, Nair BG, Maekawa T, Yoshida $\mathrm{Y}$ and Kumar DS. Nanoparticulatematerial delivery to plants. Plant Sci. 2010; 179: 154 - 163.

91. Ponti J, Colognato R., Rauscher H., Gioria S., Broggi F., Franchini F., Pascual C.,
Giudetti G. and Rossi F. Colony Forming Efficiency and Microscopy Analysis of Multiwall Carbon Nanotubes Cell Interaction. Toxicol. Lett. 2010; 197: 29-37.

92. Jalalpour Z., Shabani L., Afghani L., Sharifi-Tehrani M. and Amini S.A. Stimulatory Effect of Methyl Jasmonate and Squalestatin on Phenolic Metabolism through Induction of LOX Activity in Cell Suspension Culture of Yew. Turk. J. Biol. 2014; 38: 76 -82.

93. Khodakovskaya M.V., De-Silva K., Nedosekin D.A., Dervishi E., Biris A.S., Shashkov E.V., Galanzha E.I. and Zharov V.P. Complex Genetic, Photothermal, and Photoacoustic Analysis of Nanoparticle-plant Interactions, Proc. Natl. Acad. Sci. U.S.A. 2011; 108: 1028-1033.

94. Low P.S. and Merida J.R. The Oxidative Burst in Plant Defense: Function and Signal Transduction. Physiol. Plant 1996; 96: 533 -542.

95. Jabs T., Tschope M., Colling C., Hahlbrock K. and Scheel D. Elicitorstimulated Ion Fluxes and $\mathrm{O}_{2}{ }^{-}$from the Oxidative Burst are Essential Components in Triggering Defense Gene Activation and Phytoalexin Synthesis in Parsley. Proc. Natl. Acad. Sci. U.S.A. 1997; 94: 4800 - 4805.

96. Chong T.M., Abdullah, M.A., Lai Q.M., NorAini F.M. and Lajis N.H. Effective Elicitation Factors in Morinda elliptica Cell Suspension Culture. Process Biochem. 2005; 40: 3397 - 3405.

97. Marslin G, Caroline J, Sheeba C.J and Franklin G. Nanoparticles Alter Secondary Metabolism in Plants via ROS Burst. Frontiers in Plant Sci. 2017; 8: Article 832.

98. Sosan A., Svistunenko D., Straltsova D., Tsiurkina K., Smolich I., Lawson T. and et al. 
Engineered silver nanoparticles are sensed at the plasma membrane and dramatically modify the physiology of Arabidopsis thaliana plants. Plant J. 2016; 85: 245 - 257.

99. Mirzajani F., Askari H., Hamzelou S., Schober Y., Rompp A., Ghassempour A. and et al. Proteomics study of silver nanoparticles toxicity on Oryza sativa L. Ecotoxicol. Environ. Saf. 2014; 108: 335 - 339.

100. Khan M.N., Mobin M., Abbas Z.K., Almutairi K.A. and Siddiqui Z.H. Role of nanomaterials in plants under challenging environments. Plant Physiol. Biochem. 2017; 110: 194 - 209.

101. Vasconsuelo A. and Boland R. Molecular aspects of the early stages of elicitation of secondary metabolites in plants. Plant Sci. 2007; 172: 861 - 875.

102. Schluttenhofer C. and Yuan L. Regulation of specialized metabolism by WRKY transcription factors. Plant Physiol. 2015; 167: 295 - 306.

103. Phukan U.J., Jeena G.S. and Shukla R.K. WRKY transcription factors: molecular regulation and stress responses in plants. Front. Plant Sci. 2016; 7: 760.

104. Eom H.-J. and Choi J. p38 MAPK activation, DNA damage, cell cycle arrest and apoptosis as mechanisms of toxicity of silver nanoparticles in Jurkat T cells. Environ. Sci. Technol. 2010; 44: 8337 - 8342.

105. Lim D., Roh J.Y., Eom H.J., Choi J.Y., Hyun J. and Choi J. Oxidative stress-related PMK-1 P38 MAPK activation as a mechanism for toxicity of silver nanoparticles to reproduction in the nematode Caenorhabditis elegans. Environ. Toxicol. Chem. 2012; 31: 585 - 592.
106. Kohan-Baghkheirati E. and Geisler-Lee J. Gene expression, protein function and pathways of Arabidopsis thaliana responding to silver nanoparticles in comparison to silver ions, cold, salt, drought, and heat. Nanomaterials 2015; 5: 436 - 467.

107. Abdel-Lateif K., Bogusz D. and Hocher V. The role of flavonoids in the establishment of plant roots endosymbioses with arbuscular mycorrhiza fungi, rhizobia and Frankia bacteria. Plant Signal. Behav. 2012; 7: 636 -641.

108. Franklin G., Conceição L.F.R., Kombrink E. and Dias A.C.P. Xanthone biosynthesis in Hypericum perforatum cells provides antioxidant and antimicrobial protection upon biotic stress. Phytochemistry 2009; 70: 60 - 68 .

109. Ramakrishna A. and Ravishankar G.A. Influence of abiotic stress signals on secondary metabolites in plants. Plant Signal. Behav. 2011; 6: 1720 - 1731.

110. Briskin D.P. Medicinal plants and phytomedicines. Linking plant biochemistry and physiology to human health. Plant Physiol. 2000; 124: 507 - 514.

111. Jasim B., Thomas R., Mathew J. and Radhakrishnan E.K. Plant growth and diosgenin enhancement effect of silver nanoparticles in Fenugreek (Trigonella foenum-graecum L.). Saudi Pharm. J. 2017; 25: 443 - 447.

112. Krishnaraj C, Jagan EG, Ramachandran R, Abirami SM, Mohan N and Kalaichelvan PT. Effectof biologically synthesized silver nanoparticles on Bacopa monnieri (Linn.) Wettst. plantgrowth metabolism. Process Biochem. 2012; 47: 651 - 658. 
113. Shakeran Z, Keyhanfar M, Asghari G and Ghanadian M. Improvement of atropine production by different biotic and abiotic elicitors in hairy root cultures of Datura metel. Turk. J. Biol. 2015; 39: 111 - 118.

114. Yasur J. and Rani P.U. Environmental Effects of Nanosilver: Impact on Castor Seed Germination, Seedling Growth, and Plant Physiology. Environ. Sci. Pollut. Res. 2013; 20: 8636 - 8648.

115. Corral-Diaz B., Peralta-Videa J.R., Alvarez-Parrilla E., Rodrigo-Garcia J., Morales M.I., Osuna-Avila P., Niu G., Hernandez-Viezcas J.A. and GardeaTorresdey J.L. Cerium Oxide Nanoparticles Alter the Antioxidant Capacity but do not Impact Tuber Ionome in Raphanus sativus L. Plant Physiol. Biochem. 2014; 84: 277-285.

116. Zhao L., Huang Y., Hu J., Zhou H., Adeleye A.S. and Keller AA. 1H NMR and GC-MS Based Metabolomics Reveal Defense and Detoxification Mechanism of Cucumber Plant under Nano-Cu Stress. Environ. Sci. Technol. 2016; 50: 2000-2010.

117. Vecerova K, Vecera Z, Docekal B, Oravec M, Pompeiano A, Triska J and Urban O. Changes of primary and secondary metabolites in barley plants exposed to $\mathrm{CdO}$ nanoparticles. Environmental Pollution 2016; 218: 207-218.

118. Tan W, Du W, Ana C.B, Armendariz Jr. R, Zuverza-Mena N, Ji Z, Chang CH, Zink JI, Hernandez-Viezcas JA, Peralta-Videa JR and Gardea-Torresdey JL. Surface coating changes the physiological and biochemical impacts of nano- $\mathrm{TiO}_{2}$ in basil (Ocimum basilicum) plants. 2017; 222: 64-72.
119. Chegini E., Ghorbanpour M., Hatam M. and Taghizadeh M. Effect of Multi-Walled Carbon Nanotubes on Physiological Traits, Phenolic Contents and Antioxidant Capacity of Salvia mirzayanii Rech. f. \& Esfand. under Drought Stress. J. Med. Plants 2017; 16 (2): 191-207.

120. Hatami M., Hosseini SM., Ghorbanpour M., and Kariman K. Physiological and antioxidative responses to GO/PANI nanocomposite in intact and demucilaged seeds and young seedlings of Salvia mirzayanii. Chemosphere 2019; 233: 920-935. 121. Tian H., Ghorbanpour M., and Kariman K. Manganese oxide nanoparticle-induced changes in growth, redox reactions and elicitation of antioxidant metabolites in deadly nightshade (Atropa belladonna L.). Industrial Crops and Products 2018; 126: 403-414.

122. Beulah P., Jinu U., Ghorbanpour M., and Venkatachalam P. Green Engineered Chitosan Nanoparticles and Its Biomedical Applications-An Overview. In: M. Ghorbanpour and SH. Wani (eds.), Advances in Phytonanotechnology: From Synthesis to Application. Elsevier Academic Press. 2019; DOI: 10.1016/B978-0-12-815322-2.00015-8.

123. Rastogi A., Tripathi D.K., Yadav S., Chauhan D.K., Živčák M., Ghorbanpour M., El-Sheery N.I., and Brestic M. Application of silicon nanoparticles in agriculture. 3Biotech 2019; 9:90.

124. Fahimirad S., Ajalloueian F., and Ghorbanpour M. Synthesis and therapeutic potential of silver nanomaterials derived from plant extracts. Ecotoxicology and Environmental Safety 2019; 168: 260-278. 